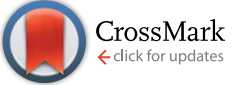

Cite this: RSC Adv., 2017, 7, 17599

Received 24th January 2017

Accepted 15th March 2017

DOI: $10.1039 / c 7 r a 01077$

rsc.li/rsc-advances

\section{A wheat straw cellulose based semi-IPN hydrogel reactor for metal nanoparticles preparation and catalytic reduction of 4-nitrophenol}

\begin{abstract}
Jianzi Ding, Qian Li, ${ }^{*}$ Liwei Zhao, Xiaodi Li, Qinyan Yue and Baoyu Gao
A wheat straw cellulose-g-poly(acrylic acid)/poly(vinyl alcohol) semi-IPN hydrogel (WSC-g-PAA/PVA) was synthesized. Copper and nickel nanoparticles were prepared in situ inside the above hydrogel and then applied as a catalyst to reduce 4-nitrophenol (4-NP). Scanning electron microscopy (SEM), energy dispersion spectrum (EDS), transmission electron microscopy (TEM), Fourier transform infrared spectroscopy (FTIR), thermal gravimetric analysis (TGA) and diffraction analysis (XRD) were employed to characterize the hydrogel-nanometal composite. The operation parameters on reduction of 4-NP were optimized by using the well-known response surface methodology (RSM) based on Box-Behnken design (BBD). Three experimental parameters including reaction temperature, the amount of hydrogel-M (metal) and the amount of $\mathrm{NaBH}_{4}$ on the 4-NP reduction were evaluated. The optimal values of the operation parameters under the related constraint conditions were obtained at $30{ }^{\circ} \mathrm{C}$ with $0.07 \mathrm{~g}$ of catalyst and $0.07 \mathrm{~g}$ of $\mathrm{NaBH}_{4}$ for hydrogel- $\mathrm{Cu}$, and at $30{ }^{\circ} \mathrm{C}$ with $0.08 \mathrm{~g}$ of catalyst and $0.12 \mathrm{~g}$ of $\mathrm{NaBH}_{4}$ for hydrogel-Ni. It was found that the activation energies were $17.30 \mathrm{~kJ} \mathrm{~mol}^{-1}$ and $19.48 \mathrm{~kJ} \mathrm{~mol}^{-1}$ for hydrogel- $\mathrm{Cu}$ and hydrogel- $\mathrm{Ni}$, respectively, by the analysis of thermodynamics of the reduction reaction. According to the 5 repetitive uses, hydrogel-Cu possessed $98 \%$ activity and hydrogel-Ni had $97 \%$ activity. And, after being stored for 30 days, both composites retained $70 \%$ activity.
\end{abstract}

\section{Introduction}

Nitroaromatic compounds are toxic organic pollutants and are widely produced as intermediates or by-products from dyes, agrochemicals, pharmaceuticals and so on. ${ }^{1-3}$ They can cause serious environmental and ecological problems. Among them, 4-nitrophenol (4-NP), the phenol derivatives, is a primary pollutant due to its high toxicity, stability and resistance to biodegradation. ${ }^{4,5}$ Many methods for 4-nitrophenol treatment have been developed including the traditional biological and chemical method, electrochemical technique, physical adsorption and so on. ${ }^{6-9}$ But the low degradation rate is the major disadvantage to treating non-degradable organic contaminants. Converting 4-NP to the available aromatic amines 4-aminophenol (or $p$-aminophenol: 4-AP) has significance. 4-AP has been applied to many industries and it is traditionally obtained by the reduction of 4-NP. For this purpose, metallic nanoparticles including $\mathrm{Pd}, \mathrm{Co}, \mathrm{Au}, \mathrm{Ni}, \mathrm{Ag}$ and so on are utilized as catalysts to reduction of 4-nitrophenol. ${ }^{10-14}$

However, the major problem in the practical use of metallic nanoparticles is that the severe aggregation of catalytic process lead to the decline of the degradation of performance in the

Shandong Provincial Key Laboratory of Water Pollution Control and Resource Reuse, School of Environmental Science and Engineering, Shandong University, Jinan 250100, China. E-mail: qianli@sdu.edu.cn; Fax: +86-531-88364513; Tel: +86-531-88361337 reduction reaction. ${ }^{15}$ To overcome the shortage, some carriers were utilized to prepare metal nanoparticles such as resins and zeolites. ${ }^{16,17}$ Among them, in virtue of the soft, elastic and flexible natural property, hydrogels have received intensive attention. Hydrogel is a hydrophilic polymer with three-dimensional (3D) network structure. The hydrophilicity of the network is attributed to the hydrophilic groups, such as $-\mathrm{COOH},-\mathrm{OH}$, $-\mathrm{NH}_{2},-\mathrm{CONH}_{2}, \mathrm{SO}_{3} \mathrm{OH}$ and $-\mathrm{CONH}-$, which are introduced into the hydrogel by cross-linking. ${ }^{18}$ Due to the hydrophilic nature of activity groups, hydrogel became an excellent template material for metal nanoparticle preparation.

Some natural macromolecules, such as cellulose, protein, starch, have been applied to prepare hydrogels. Among them, cellulose based hydrogels has more advantages as green materials due to the biodegradability and low cost. ${ }^{19}$ And the interactions between the carriers and metal nanoparticles were enhanced due to the various functionalities and porosities in cellulose hydrogels. The gel strength is also vital for the catalytic reduction of various organic pollutants with hydrogel as a reactor. Thus, intensive research effort has been devoted to the fabrication of cellulose based hydrogels. Semiinterpenetrating polymer network (semi-IPN) was a high performance material and it was composed by penetration on a molecular scale of polymer networks (the polymer was synthesized by crosslinking) with some linear or branched macromolecules. ${ }^{20}$ There is no chemical band between the two 
components of the semi-IPN, each of which possesses respective properties. So, semi-IPN shows better properties than either of the polymer alone. Recently, we have reported the preparation of the smart cellulose based semi-IPN hydrogel by wheat straw, i.e. cellulose- $g$-poly(acrylic acid)/poly(vinyl alcohol) semiIPN hydrogel (WSC-g-PAA/PVA), which possessed good gel mechanical strength and swelling capacity, presented excellent properties in water retention and metal ions adsorption and separation. ${ }^{21-23}$ So, in this study, we use wheat straw cellulose as skeleton to prepared three-dimensional network structure (hydrogel). The hydrogel worked as a carrier to fix metal nanoparticles and the hydrogel-M (M: metal (Cu or Ni)) composites was applied to reduce 4-NP to 4-AP. During the entire process of experiment, we have made good use of waste material, recycling the metal ions from aqueous solution and converting 4-NP (toxic organic pollutant) to available 4-AP.

In the reduction experiments, the reduction of 4-NP could be influenced by multiple reaction conditions. The traditional optimization experiment is time-consuming and expensive and does not consider the interactions between the factors. As a statistical-based analytical technique, response surface methodology (RSM) has been applied successfully to explain the interaction between reaction parameters. Compared with other designs of RSM, Box-Behnken design (BBD) is the most frequently employed and offers some advantages such as reducing the study time, operating at a high efficiency and predicting results close to the actual experimental data. ${ }^{24}$ Thus, in the present work, a BBD was applied to determine the optimum 4-NP reduction performance, and also to explain the relationships between 4-NP reduction and three pertinent parameters, namely, reaction temperature, the amount of hydrogel-M composite and the amount of $\mathrm{NaBH}_{4}$.

\section{Experimental}

\subsection{Materials}

Acrylic acid (AA), poly(vinyl alcohol) (PVA), potassium hydroxide $(\mathrm{KOH})$, sodium sulfite $\left(\mathrm{Na}_{2} \mathrm{SO}_{3}\right)$, ammonium cerium nitrate $\left(\left(\mathrm{NH}_{4}\right)_{2} \mathrm{Ce}\left(\mathrm{NO}_{3}\right)_{6}\right)$, potassium persulfate $\left(\mathrm{K}_{2} \mathrm{~S}_{2} \mathrm{O}_{8}\right), N, N^{\prime}$-methylenebisacrylamide (MBA), 4-nitrophenol (4-NP), $\mathrm{NaBH}_{4}$, $\mathrm{Cu}\left(\mathrm{NO}_{3}\right)_{2} \cdot 3 \mathrm{H}_{2} \mathrm{O}$ and $\mathrm{Ni}\left(\mathrm{NO}_{3}\right)_{2} \cdot 6 \mathrm{H}_{2} \mathrm{O}$ were of analytical grade and purchased from Kemiou Chemical Regent factor, Tianjin, China and wheat straw was gained from Liaocheng, China.

\subsection{Hydrogel synthesis}

The preparation method of crosslinking WSC- $g$-PAA/PVA hydrogel has been reported earlier. ${ }^{25}$ In brief, $1.0 \mathrm{~g}$ WSC with $\mathrm{K}_{2} \mathrm{~S}_{2} \mathrm{O}_{8}$ and $\left(\mathrm{NH}_{4}\right)_{2} \mathrm{Ce}\left(\mathrm{NO}_{3}\right)_{6}$ were simultaneously added into three-necked flask installed with an electric stirrer and placed in a water bath keeping temperature at $50{ }^{\circ} \mathrm{C}$. After $15 \mathrm{~min}$, $\mathrm{Na}_{2} \mathrm{SO}_{3}$ and a mixture (AA and $\mathrm{KOH}$ ) were slowly added into the above solution. After 15 min, PVA was mixed into the flask, after $45 \mathrm{~min}, \mathrm{MBA}$ as crosslinker was added and reaction sustained for $4 \mathrm{~h}$. The wet sample was obtained and dried at $75^{\circ} \mathrm{C}$. Then, the samples were crushed and sieved through a 20 to 40 mesh for further use.

\subsection{Preparation of metal nanoparticles in WSC- $g$-PAA/PVA semi-IPNs hydrogel}

$100 \mathrm{mg}$ dried WSC-g-PAA/PVA hydrogel was added into $50 \mathrm{~mL}$ of $0.05 \mathrm{M}$ metal solutions ( $\mathrm{Cu}(\mathrm{II})$ or $\mathrm{Ni}(\mathrm{II})$ ) and the adsorption experiment was conducted in a constant temperature incubator shaker BPN-25HL at $25{ }^{\circ} \mathrm{C}$ for $4 \mathrm{~h}$. The hydrogels of containing metal ions were shifted into distilled water for $2 \mathrm{~h}$ to remove unbound metal ions from the above hydrogel. Then, the loaded hydrogel were moved into $\mathrm{NaBH}_{4}(0.1 \mathrm{M} 50 \mathrm{~mL})$ solution for $2 \mathrm{~h}$ until completed reduction of metal ions to metal nanoparticles in situ and then were washed with DW over night. The obtained hydrogel-nanometal composite was named as hydrogel-M (M: Cu or Ni). The amount of metal nanoparticle embodied in the hydrogel was determined as followed: $0.1 \mathrm{~g}$ hydrogel-M was placed into $100 \mathrm{~mL} 5 \mathrm{M} \mathrm{HCl}$ to elute the metal of adsorption completely; then the concentration of $\mathrm{Cu}$ (II) or $\mathrm{Ni}$ (II) was determined by Atomic Absorption Spectroscopy (AAS) on TAS-990 instrument. The experimental result suggested $1 \mathrm{~g}$ hydrogel-M contained $177.0 \mathrm{mg}$ copper and $156.1 \mathrm{mg}$ nickel, respectively.

\subsection{Characterization}

The surface morphology of sample was obtained in a SEM instrument (FEI quanta feg 250) and the elemental components were examined by EDS. The thermal gravimetric analysis (TGA) was measured using a TGA instrument (SHI-MADZU, TGA-50) by heating the sample between $25{ }^{\circ} \mathrm{C}$ and $600{ }^{\circ} \mathrm{C}$ with the rate of $10{ }^{\circ} \mathrm{C} \mathrm{min}^{-1}$ under nitrogen condition. X-ray diffraction (XRD) was obtained from an Empyrean XRD instrument (D8 ADVANCE). TEM was performed from a JEM 2100 instrument. The FTIR was acquired from a NEXUS-470 spectrometer.

\subsection{Reduction of 4-NP catalyzed by hydrogel-M}

$200 \mathrm{~mL} 50 \mathrm{mg} \mathrm{L}^{-1} 4$-NP containing certain $\mathrm{NaBH}_{4}$ was prepared and placed in a $500 \mathrm{~mL}$ beaker. An appropriate dosage of hydrogel-M composite was added into this solution as a catalyst system in the generation of active hydrogen atoms in hydrolysis of $\mathrm{NaBH}_{4}$ and the 4-NP was reduced to 4-AP by hydrogen atoms. To determine the reduction rate of $4-\mathrm{NP}, 0.5 \mathrm{~mL}$ sample was taken from the beaker every $5 \mathrm{~min}$; then the sample was diluted to a suitable concentration to detect the amount of residual 4$\mathrm{NP}$ at $400 \mathrm{~nm}$ absorbance value in a UV-Vis spectrometer. To assess the effect of temperature, hydrogel-M dosage and the amount of $\mathrm{NaBH}_{4}$ on the conversion of 4-NP to 4-AP, the reduction reactions were carried out at different temperatures $\left(30,40,50\right.$, and $\left.60{ }^{\circ} \mathrm{C}\right)$, different dosage of hydrogel-M (0.05, $0.10,0.15,0.20 \mathrm{~g})$ and different amount of $\mathrm{NaBH}_{4}(0.05,0.10$, $0.15,0.20 \mathrm{~g}$ ) respectively.

To investigate the reusability of the catalyst, the same hydrogel-M was utilized five times consecutively for the reduction reactions and washed with DW before next use. The storage capacity of the catalyst was determined by keeping the hydrogel-M composite in a $50 \mathrm{~mL}$ closed container with distilled water at $25{ }^{\circ} \mathrm{C}$. 
Table 1 Experimental range and level of independent variables for reduction 4-NP by hydrogel-Cu and hydrogel-Ni as catalyst

\begin{tabular}{|c|c|c|c|c|c|c|}
\hline \multirow[b]{3}{*}{ Independent variable $x$} & \multicolumn{6}{|c|}{ Range and level } \\
\hline & \multicolumn{3}{|c|}{ Hydrogel-Cu } & \multicolumn{3}{|c|}{ Hydrogel-Ni } \\
\hline & -1 & 0 & 1 & -1 & 0 & 1 \\
\hline$x_{1}$; temperature $\left({ }^{\circ} \mathrm{C}\right)$ & 30 & 45 & 60 & 30 & 45 & 60 \\
\hline$x_{2} ;$ catalyst amounts $(\mathrm{g})$ & 0.01 & 0.08 & 0.15 & 0.05 & 0.13 & 0.20 \\
\hline$x_{3} ; \mathrm{NaBH}_{4}(\mathrm{~g})$ & 0.05 & 0.10 & 0.15 & 0.05 & 0.13 & 0.20 \\
\hline
\end{tabular}

\subsection{Experimental design by BBD}

The experiment could be divided into two parts. In the first part, a series of single factor experiments were performed with the purpose of getting the best value range of independent variables for the second part. Three experimental parameters (i.e. temperature, the amount of hydrogel-M and the amount of $\mathrm{NaBH}_{4}$ ) as independent variables were considered with reduction rate as dependent variable. Then, according to the result of first part, multifactor interaction experiment was designed and carried out by BBD. Reduction rate as response value, the three independent variables were: temperature $\left({ }^{\circ} \mathrm{C}\right)$, the amount of hydrogel- $\mathrm{M}(\mathrm{g})$ and the amount of $\mathrm{NaBH}_{4}(\mathrm{~g})$. From the first part of experiment, we found the catalytic efficiency of hydrogel-Cu was better than that of hydrogel-Ni in the same condition and the value range of each independent variable was different between them. The values of different variables were shown in Table 1 and 17 groups of experiments were designed and shown in Tables 2 and 3. A second-order model in the form of quadratic polynomial equation was used to describe response value.

$$
Y=\alpha_{0}+\sum_{i=1}^{n=3} \alpha_{i} x_{i}+\sum_{i=1, i=1}^{n=3} \alpha_{i i} x_{i}^{2}+\sum_{i=1, j=1}^{n=3} \alpha_{i j} x_{i} x_{j}
$$

Table 2 Experimental results and predictive values by hydrogel-Cu as catalyst

\begin{tabular}{|c|c|c|c|c|c|}
\hline \multirow[b]{2}{*}{ Run } & \multicolumn{3}{|c|}{ Experimental conditions } & \multicolumn{2}{|c|}{4 -NP reduction rate $(\%)$} \\
\hline & $x_{1} T$ & $x_{2}$ hydrogel-Cu & $x_{3} \mathrm{NaBH}_{4}$ & Experimental & Predictive \\
\hline 1 & $45(0)$ & $0.08(0)$ & $0.10(0)$ & 99.46 & 99.41 \\
\hline 2 & $45(0)$ & $0.08(0)$ & $0.10(0)$ & 98.65 & 99.41 \\
\hline 3 & $45(0)$ & $0.15(+1)$ & $0.15(+1)$ & 98.26 & 98.34 \\
\hline 4 & $60(+1)$ & $0.08(0)$ & $0.05(-1)$ & 73.79 & 73.19 \\
\hline 5 & $45(0)$ & $0.01(-1)$ & $0.15(+1)$ & 90.59 & 89.67 \\
\hline 6 & $60(+1)$ & $0.15(+1)$ & $0.10(0)$ & 98.74 & 98.42 \\
\hline 7 & $45(0)$ & $0.08(0)$ & $0.10(0)$ & 99.74 & 99.41 \\
\hline 8 & $30(-1)$ & $0.15(+1)$ & $0.10(0)$ & 99.19 & 98.51 \\
\hline 9 & $45(0)$ & $0.08(0)$ & $0.10(0)$ & 99.74 & 99.41 \\
\hline 10 & $45(0)$ & $0.15(+1)$ & $0.05(-1)$ & 99.86 & 100.78 \\
\hline 11 & $30(-1)$ & $0.01(-1)$ & $0.10(0)$ & 54.31 & 54.63 \\
\hline 12 & $60(+1)$ & $0.01(-1)$ & $0.10(0)$ & 59.45 & 60.13 \\
\hline 13 & $30(-1)$ & $0.08(0)$ & $0.15(+1)$ & 99.87 & 100.47 \\
\hline 14 & $45(0)$ & $0.01(-1)$ & $0.05(-1)$ & 27.36 & 27.28 \\
\hline 15 & $60(+1)$ & $0.08(0)$ & $0.15(+1)$ & 99.33 & 99.58 \\
\hline 16 & $45(0)$ & $0.08(0)$ & $0.10(0)$ & 99.46 & 99.41 \\
\hline 17 & $30(-1)$ & $0.08(0)$ & $0.05(-1)$ & 67.15 & 66.91 \\
\hline
\end{tabular}

Table 3 Experimental results and predictive values by hydrogel-Ni as catalyst

\begin{tabular}{llllllc}
\hline & \multicolumn{3}{c}{ Experimental conditions } & & & 4-NP reduction rate (\%) \\
\cline { 2 - 3 } Run & $x_{1} T$ & $x_{2}$ hydrogel-Ni & $x_{3} \mathrm{NaBH}_{4}$ & & Experimental & Predictive \\
\hline 1 & $30(-1)$ & $0.13(0)$ & $0.20(+1)$ & 99.06 & 100.75 \\
2 & $45(0)$ & $0.20(+1)$ & $0.05(-1)$ & 97.30 & 98.12 \\
3 & $45(0)$ & $0.13(0)$ & $0.13(0)$ & 96.65 & 95.95 \\
4 & $30(-1)$ & $0.05(-1)$ & $0.13(0)$ & 85.00 & 83.38 \\
5 & $60(+1)$ & $0.13(0)$ & $0.20(+1)$ & 95.18 & 95.92 \\
6 & $60(+1)$ & $0.05(-1)$ & $0.13(0)$ & 93.92 & 93.25 \\
7 & $45(0)$ & $0.05(-1)$ & $0.20(+1)$ & 98.92 & 98.86 \\
8 & $30(-1)$ & $0.13(0)$ & $0.05(-1)$ & 79.62 & 78.89 \\
9 & $45(0)$ & $0.05(-1)$ & $0.05(-1)$ & 70.83 & 73.19 \\
10 & $45(0)$ & $0.13(0)$ & $0.13(0)$ & 96.85 & 95.95 \\
11 & $60(+1)$ & $0.20(+1)$ & $0.13(0)$ & 97.30 & 97.37 \\
12 & $60(+1)$ & $0.13(0)$ & $0.05(-1)$ & 95.14 & 93.45 \\
13 & $45(0)$ & $0.13(0)$ & $0.13(0)$ & 92.03 & 95.95 \\
14 & $30(-1)$ & $0.20(+1)$ & $0.13(0)$ & 98.38 & 99.05 \\
15 & $45(0)$ & $0.13(0)$ & $0.13(0)$ & 96.76 & 95.95 \\
16 & $45(0)$ & $0.13(0)$ & $0.13(0)$ & 97.44 & 95.95 \\
17 & $45(0)$ & $0.20(+1)$ & $0.20(+1)$ & 98.38 & 96.02
\end{tabular}

where $Y$ was the predict of response value (the reduction rate of 4-NP); $\alpha_{0}$ was constant coefficient; $\alpha_{i}, \alpha_{i i}$ and $\alpha_{i j}$ were regression coefficient; $x_{i}$ and $x_{j}$ were the independent variables.

\section{Results and discussion}

\subsection{Characterization}

The surface morphologies of WSC- $g$-PAA/PVA, WSC- $g$-PAA/PVA$\mathrm{Cu}$ and WSC- $g$-PAA/PVA-Ni were shown in Fig. 1 . It can be clearly observed that the WSC- $g$-PAA/PVA hydrogel (a) has a densely reticulate structure. The images of Fig. 1(b) and (c) indicated that WSC- $g$-PAA/PVA-Cu and WSC- $g$-PAA/PVA-Ni had spherical morphology about 20-30 nm. From the images, it proved that $\mathrm{Cu}$ and $\mathrm{Ni}$ nanoparticles have been prepared inside hydrogel. In addition, the EDS spectrum also showed that the $\mathrm{Cu}$ and Ni nanoparticles were dispersed on the surface of the hydrogel (Fig. 2).

The TGA and DSC curves of WSC- $g$-PAA/PVA, WSC- $g$-PAA/ PVA-Cu and WSC- $g$-PAA/PVA-Ni were shown in Fig. 3. As can be seen from the chart, the pyrolysis process of WSC- $g$-PAA/PVA showed two stages. The first weight loss of $26.22 \%$ before $374{ }^{\circ} \mathrm{C}$ was due to the removal of the free water and structural water, the scission of the major and branched chains of polymer. A further weight loss of $22.09 \%$ from $374{ }^{\circ} \mathrm{C}$ to $522{ }^{\circ} \mathrm{C}$ was attributed to the final decomposition of the gels. For hydrogels which contained metal nanoparticle, the pyrolysis processes were both divided into two stages but more thermally stabilized compared with bare hydrogels (with no metal nanoparticle embedded). For WSC- $g$-PAA/PVA-Cu, the weight loss of $35.45 \%$ occurred at the first stage from $23{ }^{\circ} \mathrm{C}$ to $450{ }^{\circ} \mathrm{C}$. This may be due to the removal of the free water, structural water and the scissions of $\mathrm{C}-\mathrm{O}$ and $\mathrm{C}-\mathrm{C}$ bonds in the polymer which transformed into $\mathrm{CO}, \mathrm{CO}_{2}$ and $\mathrm{H}_{2} \mathrm{O}$. The second degradation with $2.85 \%$ until $593{ }^{\circ} \mathrm{C}$ was due to the continued decomposition of the coke structures. For WSC- $g$-PAA/PVA-Ni, the pyrolysis processes 

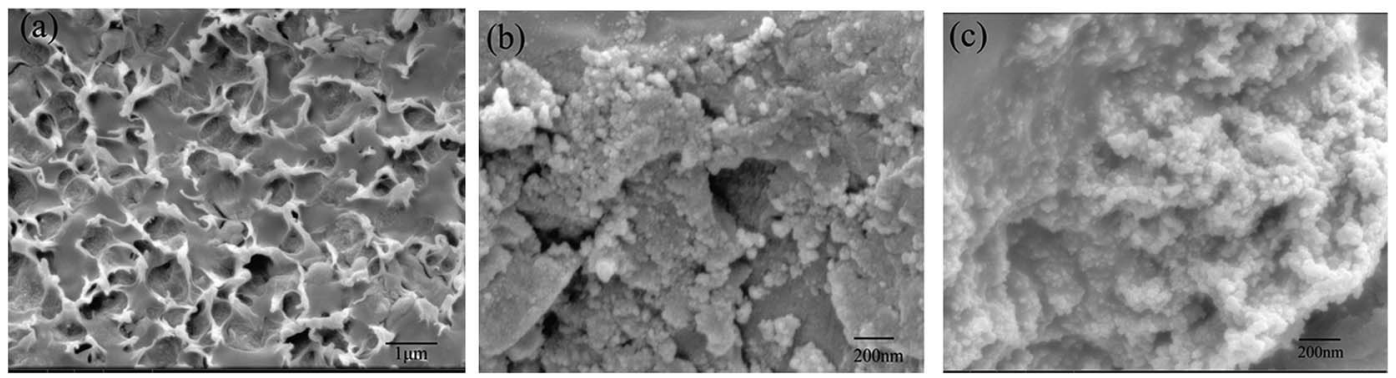

Fig. 1 SEM images of WSC-g-PAA/PVA hydrogel (a), WSC-g-PAA/PVA-Cu hydrogel (b) and WSC-g-PAA/PVA-Ni hydrogel (c).
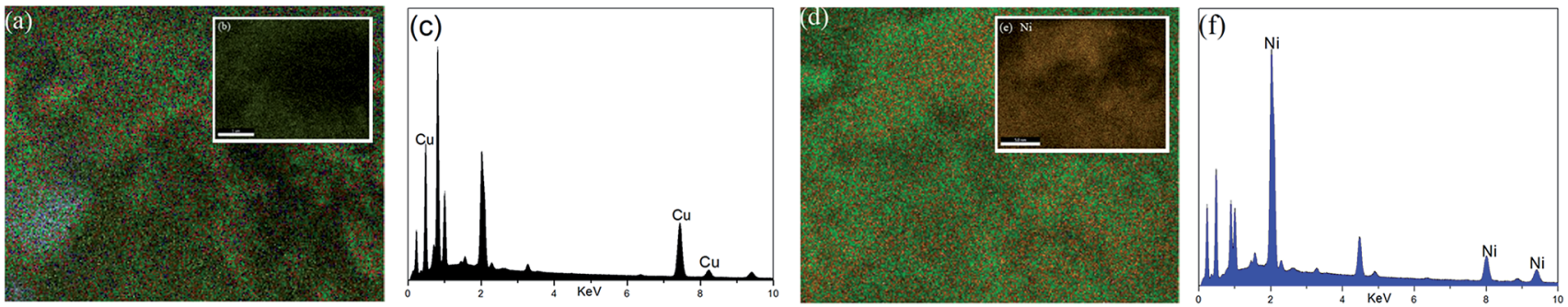

Fig. 2 EDS diagrams of WSC-g-PAA/PVA-Cu hydrogel (a)-(c) and WSC-g-PAA/PVA-Ni hydrogel (d)-(f).

also presented the similar two stages with the weight loss of $34.61 \%\left(19-447^{\circ} \mathrm{C}\right)$, and $3.28 \%\left(447-600{ }^{\circ} \mathrm{C}\right)$, respectively. Thus, the existence of metal nanoparticles within hydrogel provided fewer amounts of degradations with higher thermal stability than the bare hydrogel.

The FTIR spectra of WSC- $g$-PAA/PVA, WSC- $g$-PAA/PVA-Cu/Ni were shown in Fig. 4. A broad absorption band at $3460 \mathrm{~cm}^{-1}$ in Fig. 2(a), $3427 \mathrm{~cm}^{-1}$ in Fig. 2(b) and $3398 \mathrm{~cm}^{-1}$ in Fig. 2(c) corresponding to the stretching vibration of hydroxyl $(-\mathrm{OH})$ of PVA chains implied that the hydroxyl groups didn't participate in the grafting reaction. ${ }^{26}$ A peak observed at $510 \mathrm{~cm}^{-1}$ due to the vibration of $\mathrm{C}-\mathrm{N}-\mathrm{OH}$ demonstrated that a graft copolymerization process occurred between AA and WSC during the synthesis process of hydrogel; and the peak performed a blue-shift in the

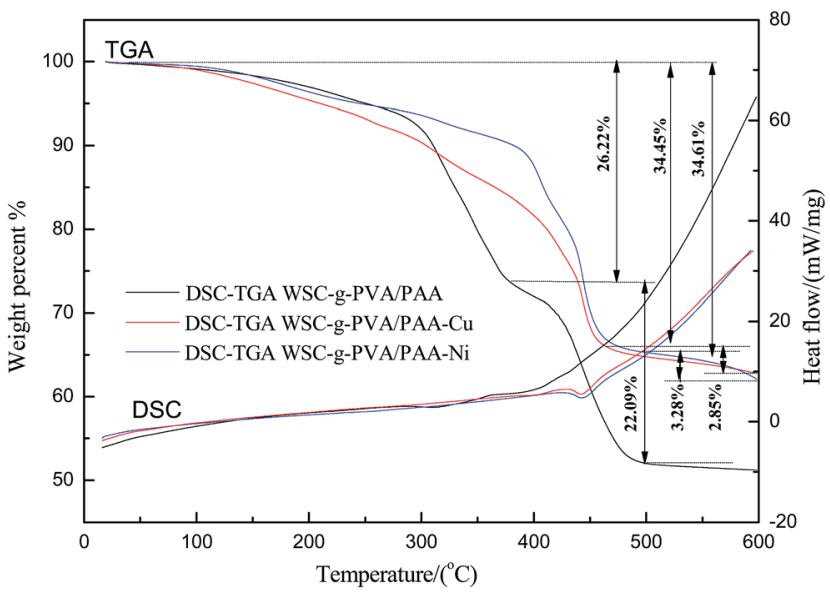

Fig. 3 TGA and DSC diagrams of WSC-g-PAA/PVA hydrogel, WSC- $g$ PAA/PVA-Cu hydrogel and WSC-g-PAA/PVA-Ni hydrogel. curves of WSC-PAA/PVA-Cu hydrogel $\left(519 \mathrm{~cm}^{-1}\right)$ and WSC-PAA/ PVA-Ni hydrogel $\left(515 \mathrm{~cm}^{-1}\right)$, respectively, attributed to the interaction between metal (Cu or Ni) nanoparticles and hydrogel networks. In the FTIR spectra, WSC- $g$-PAA/PVA, WSC-PAA/PVA$\mathrm{Cu}$ and WSC-PAA/PVA-Ni exhibited similar peaks for the asymmetric stretching vibration of methylene $\left(-\mathrm{CH}_{2}\right)$ at $2934 \mathrm{~cm}^{-1}$, $2928 \mathrm{~cm}^{-1}$ and $2948 \mathrm{~cm}^{-1},{ }^{27}$ respectively, accounting for the occurrence of crosslinking reaction. The peaks observed at 1573 $\mathrm{cm}^{-1}$ and $1396 \mathrm{~cm}^{-1}$ in WSC-g-PAA/PVA hydrogel respectively attributed to the asymmetric stretching vibration and symmetric stretching vibration of $\mathrm{COO}^{-}$groups that were transformed from $-\mathrm{COOH}$ groups in $\mathrm{AA}^{28}$ But the relevant peaks in WSC- $g$-PAA/

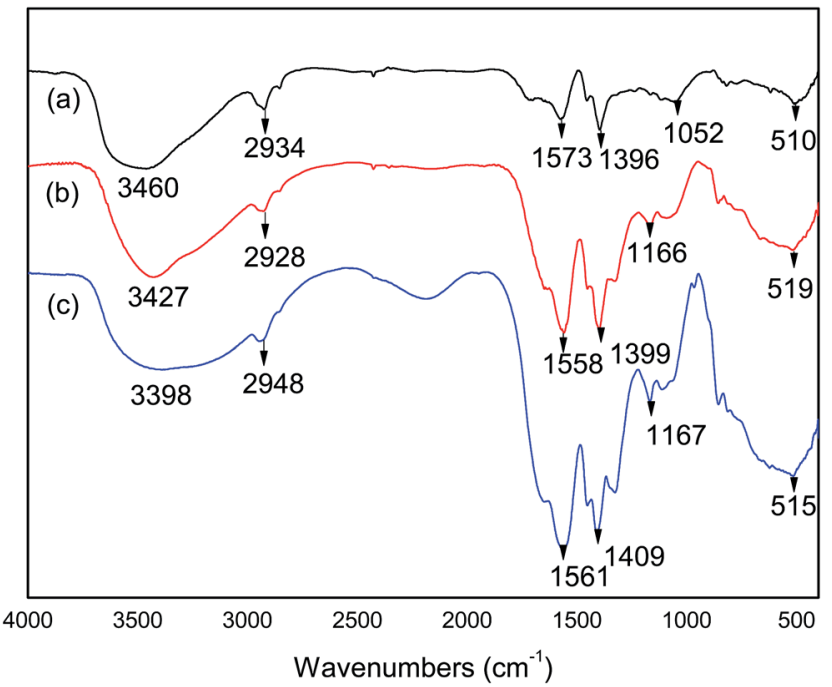

Fig. 4 FTIR of WSC-g-PAA/PVA hydrogel (a), WSC-g-PAA/PVA-Cu hydrogel (b) and WSC-g-PAA/PVA-Ni hydrogel (c). 
PVA-Cu hydrogel (Fig. 2(b)) and WSC- $g$-PAA/PVA-Ni hydrogel (Fig. 2(c)) had slight red-shift $\left(1558 \mathrm{~cm}^{-1}\right.$ and $1399 \mathrm{~cm}^{-1}$ in (b); $1561 \mathrm{~cm}^{-1}$ and $1409 \mathrm{~cm}^{-1}$ in (c)) indicating the coordination of $\mathrm{COO}^{-}$and $\mathrm{Cu}^{2+}\left(\mathrm{Ni}^{2+}\right)$. And the peaks became stronger originating from the infrared absorption of copper (nickel) metal nanoparticles, which may generate a change in photoelectric characteristics of the hydrogel surface. ${ }^{29}$ The band of $\mathrm{C}-\mathrm{OH}$ at $1052 \mathrm{~cm}^{-1}$ (stretching vibration of $\mathrm{C}-\mathrm{OH}$ in WSC (Fig. 2(a)) shifted to $1166 \mathrm{~cm}^{-1}$ (Fig. 2(b)) and $1167 \mathrm{~cm}^{-1}$ (Fig. 2(c)) and the peaks had blue-shift implying that the groups were more stable because of addition of metal nanoparticles ( $\mathrm{Cu}$ or Ni) into WSC- $g$ PAA/PVA network.

The X-ray diffraction (XRD) analysis of WSC- $g$-PAA/PVA and WSC- $g$-PAA/PVA-Cu/Ni were shown in Fig. 5. There exit no apparent peaks in the XRD image of WSC- $g$-PAA/PVA indicating no crystal structure in the gel. But for metal nanoparticles embedded hydrogels, three strong peaks were observed at $43.67^{\circ}$, $50.71^{\circ}$ and $74.14^{\circ}$ in WSC- $g$-PAA/PVA-Cu corresponding to metal $\mathrm{Cu}(111), \mathrm{Cu}(200)$ and $\mathrm{Cu}(220)$, and $44.65^{\circ}, 51.71^{\circ}$ and $78.07^{\circ}$ in the WSC- $g$-PAA/PVA-Ni consistent with metal Ni (111), Ni (200) and $\mathrm{Ni}(220)$, respectively, ${ }^{30,31}$ which all verified crystallinity of the nanoparticles. Moreover, there exited no characteristic peaks of copper (or nickel) oxides in the XRD images, indicating the fairly stability against oxidation of the metal nanoparticles due to the presence of the hydrogel capping network. Furthermore, the existence of metal nanoparticles was further evidenced by TEM images shown in Fig. 6. It is clearly observed that the $\mathrm{Cu} / \mathrm{Ni}$ nanoparticles were dispersed inside the hydrogel uniformly with a diameter of 20-30 nm. From the selected area electron diffraction patterns (SAED), the images were composed of a series of concentric circles. These demonstrated that a large number of crystal metal particles existed inside the hydrogel.

\subsection{Catalytic reduction of 4-NP}

As is known to all, a series of noble metal can be applied as catalyst to reduce 4-NP. However, the bare metal nanoparticles have severe aggregation during catalytic process. In virtue of this

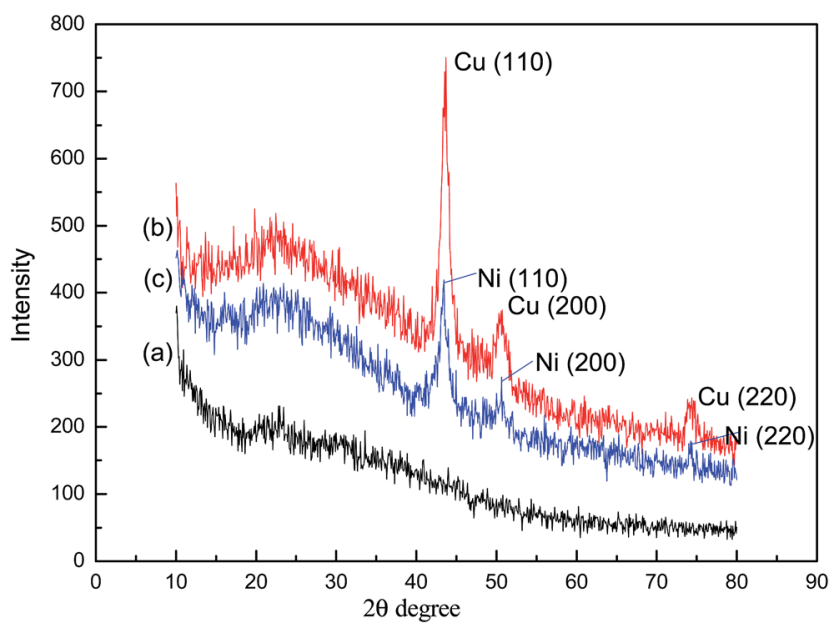

Fig. 5 XRD of WSC-g-PAA/PVA hydrogel (a), WSC-g-PAA/PVA-Cu hydrogel (b) and WSC-g-PAA/PVA-Ni hydrogel (c). constraint, the WSC- $g$-PVA/PAA hydrogel was prepared as a carrier. As shown in Fig. 7, the adsorption of $\mathrm{Cu}^{2+}$ or $\mathrm{Ni}^{2+}$ was combined with the $\mathrm{COO}^{-}$of AA and enhanced the stability of metal nanoparticles $(\mathrm{Cu}$ or $\mathrm{Ni})$. The hydrogel has a three-dimensional network structure which made the metal nanoparticles disperse uniformly inside the hydrogel and prevented the aggregation of nanoparticles. Furthermore, the reactor provided a channel that increased the contact between metal nanoparticles and reactant and promoted the efficiency of catalytic reduction.

In order to quantitatively evaluate the catalytic performance of nanometal embodied by hydrogel, the reduction of 4-NP catalyzed by WSC-g-PAA/PVA-M (M: Cu or Ni) in the presence of $\mathrm{NaBH}_{4}$ was chosen as a model reaction (Fig. 8). From the picture, the reduction rate of 4-NP with WSC-g-PAA/PVA-Cu composite as catalyst is much faster than WSC- $g$-PAA/PVA-Ni system. As shown in Fig. 9(a), 4-NP had a maximum absorption peak at $317 \mathrm{~nm}$, and then shifted to $400 \mathrm{~nm}$ immediately attributing to the formation of 4-nitrophenolate anion in alkaline condition when $\mathrm{NaBH}_{4}$ was added into the solution. ${ }^{32,33}$ It was found that the absorption intensity of 4-NP in the UV-vis cure was almost unchanged in about $60 \mathrm{~min}$. The result indicated that the 4-NP was not degraded in the absent of catalyst. By tracking the change of absorption bands by UV-Vis spectrophotometers, the reduction rate of 4-NP to 4-AP could be detected. As WSC- $g$-PAA/PVA-Cu afford the faster reduction rate of 4-NP, a typical evolution of the UV-Vis spectra observed at every 2 min with the hydrogel-Cu as catalyst was illustrated in Fig. 9(b). It can be seen that the absorption intensity was almost unchanged until the hydrogel-Cu was put into the above solution. The absorption of 4-nitrophenolate anion at $400 \mathrm{~nm}$ gradually decreased with the reaction time increasing. And a new absorption peak appeared at $300 \mathrm{~nm}$, which was the corresponding absorption peak at 4-AP, indicated the conversion of 4-NP to 4-AP occurred constantly without any side reaction. ${ }^{34}$ The reduction reaction could be completed about 14 min evidenced by the peak at $400 \mathrm{~nm}$ disappeared and the new peak at $300 \mathrm{~nm}$ no more changed.

\subsection{Analysis of response surface of the reduction reaction}

3.3.1 Analysis of the model. Two catalysts including hydrogel- $\mathrm{Cu}$ and hydrogel-Ni were used in the experiment. We made two groups of experiment and each group of experiment has 3 parameters $\left(x_{1}\right.$ : temperature, $x_{2}$ : the amount of hydrogel$\mathrm{M}, x_{3}$ : the amount of $\left.\mathrm{NaBH}_{4}\right)$. Three factors and three levels experiment was designed to obtain the optimal reduction condition of 4-NP by BBD.

The independent variables and the response values (the 4-NP reduction rate) were presented in Table 2 (hydrogel-Cu) and Table 3 (hydrogel-Ni). The following second-order model of the reduction reaction was gained with three factors.

$$
\begin{aligned}
Y_{1}= & 99.41+1.35 x_{1}+20.54 x_{2}+15 x_{3}-1.40 x_{1} x_{2}-4.79 x_{1} x_{3} \\
& -16.21 x_{2} x_{3}-7.74 x_{1}{ }^{2}-13.75 x_{2}{ }^{2}-6.64 x_{3}{ }^{2} \\
Y_{2}= & 95.95+2.43 x_{1}+5.34 x_{2}+6.08 x_{3}-2.50 x_{1} x_{2}-4.85 x_{1} x_{3} \\
& -6.75 x_{2} x_{3}-0.70 x_{1}{ }^{2}-1.59 x_{2}{ }^{2}-2.99 x_{3}{ }^{2}
\end{aligned}
$$

$\left(Y_{1}\right.$ : the reduction rate with hydrogel-Cu as catalyst, $Y_{2}$ : the reduction rate with the hydrogel-Ni as catalyst). 

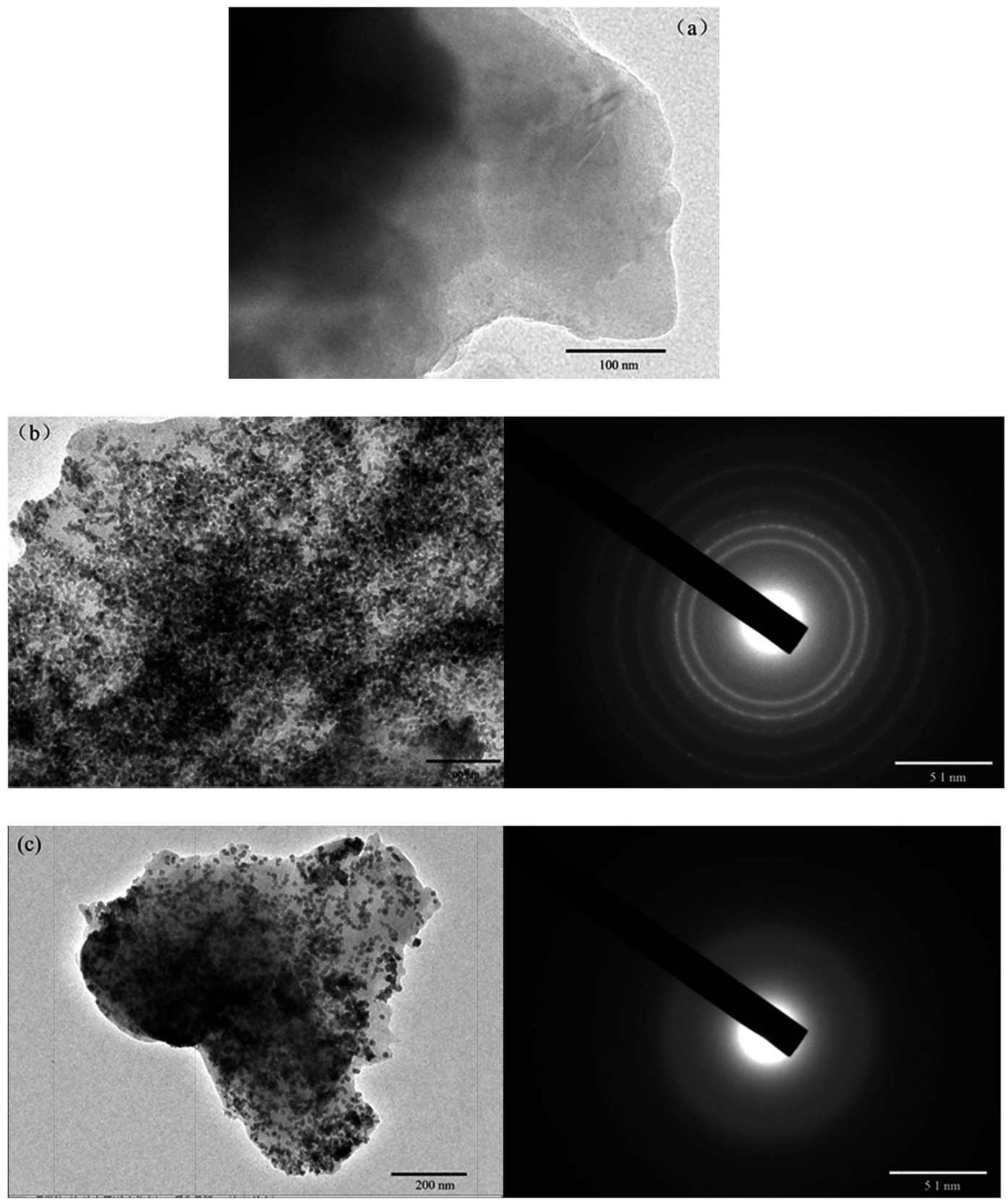

Fig. 6 TEM images of WSC-g-PAA/PVA hydrogel (a), WSC-g-PAA/PVA-Cu hydrogel (b) and WSC-g-PAA/PVA-Ni hydrogel (c).

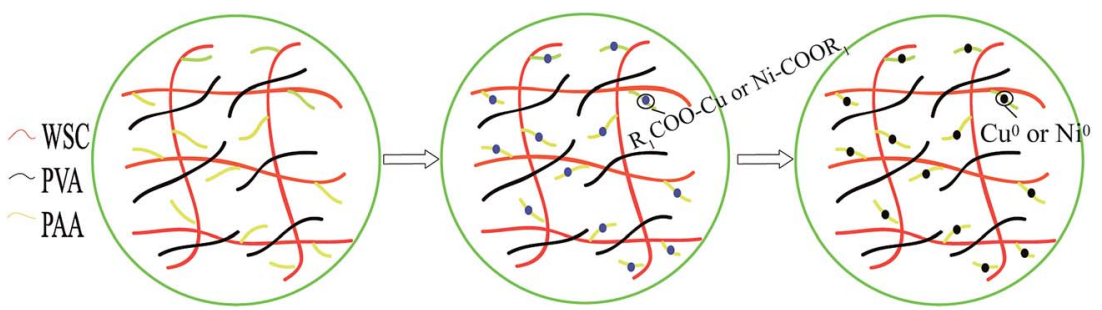

Fig. 7 The mechanism of interaction between metal nanoparticles ( $\mathrm{Cu} / \mathrm{Ni})$ and WSC-g-PVA/PAA hydrogel.

The experimental data of the variance (ANOVA) for hydrogelCu was shown in Table 4 . The model of $F$-value was 1326.51 and implied the model was significant. Furthermore, there was only a $0.01 \%$ ( $p$-value was 0.0001 ) chance that a model $F$-value may occur large change due to noise. The $p$-value less than 0.05 (ref. 35 ) indicated that the terms was significant and the values less 


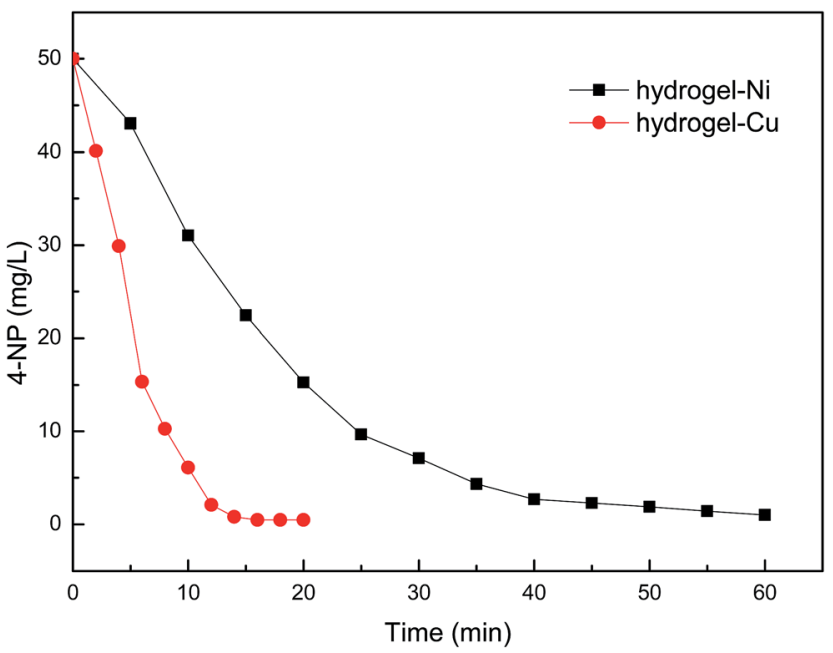

Fig. 8 The effect of different hydrogel-M as catalyst on the reduction of 4-NP.
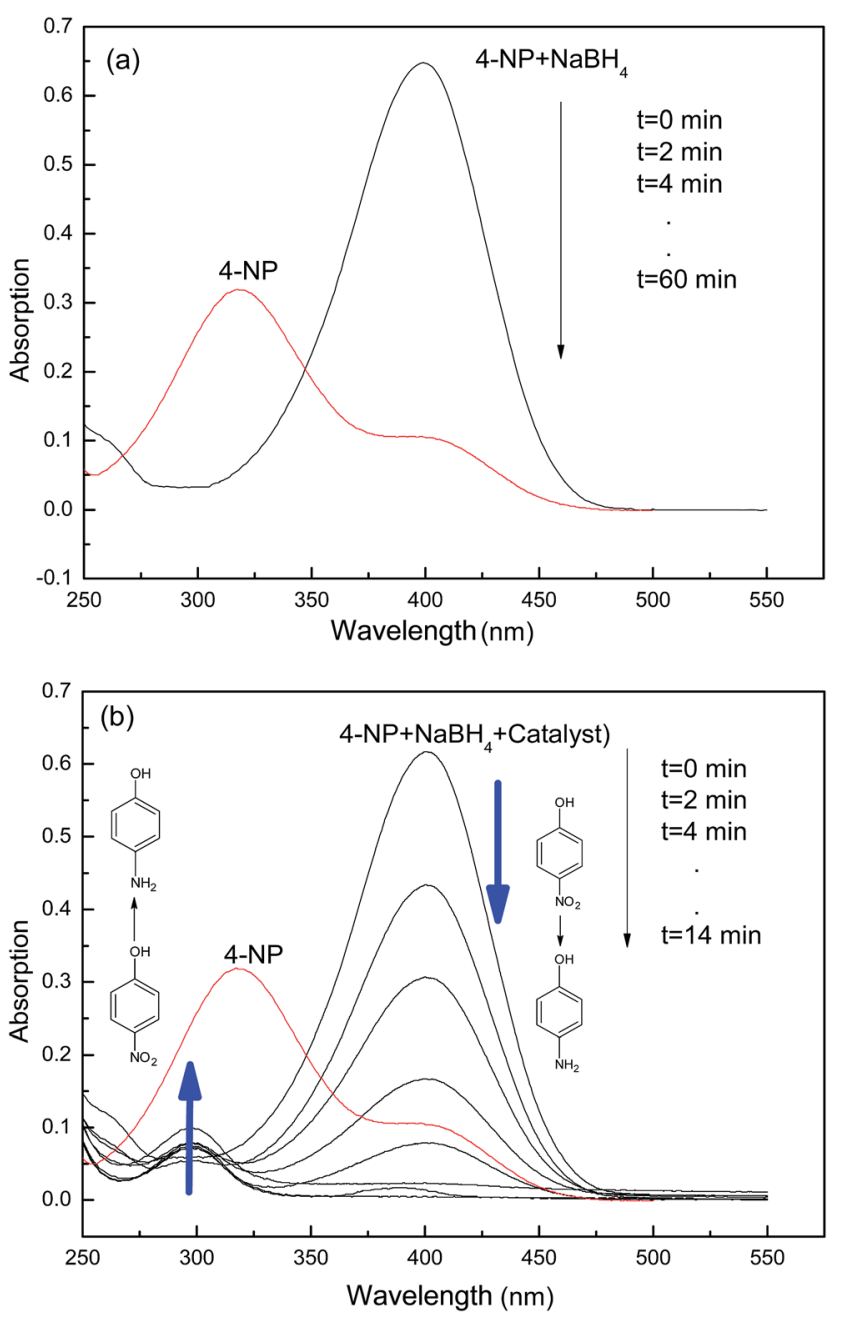

Fig. 9 UV-Vis spectra for the reduction of 4-NP to 4-AP catalyzed by hydrogel-Cu at $25^{\circ} \mathrm{C}$ without $\mathrm{NaBH}_{4}$ (a) and with $\mathrm{NaBH}_{4}$ (b).
Table 4 Analysis of variance (hydrogel-Cu) ${ }^{a}$

\begin{tabular}{|c|c|c|c|c|c|}
\hline Source & $\begin{array}{l}\text { Sum of } \\
\text { squares }\end{array}$ & $\begin{array}{l}\text { Degrees of } \\
\text { freedom }\end{array}$ & $\begin{array}{l}\text { Mean } \\
\text { square }\end{array}$ & $F$ value & $\begin{array}{l}p \text {-Value } \\
\text { Prob }>F\end{array}$ \\
\hline Model & 7617.05 & 9 & 846.34 & 1326.51 & $<0.0001$ \\
\hline$x_{1}$ & 14.55 & 1 & 14.55 & 22.80 & 0.0020 \\
\hline$x_{2}$ & 3375.95 & 1 & 3375.95 & 5291.30 & $<0.0001$ \\
\hline$x_{3}$ & 1796.76 & 1 & 1796.76 & 2816.15 & $<0.0001$ \\
\hline$x_{1} x_{2}$ & 7.81 & 1 & 7.81 & 12.24 & 0.0100 \\
\hline$x_{1} x_{3}$ & 12.88 & 1 & 12.88 & 20.19 & 0.0028 \\
\hline$x_{2} x_{3}$ & 1050.73 & 1 & 1050.73 & 1646.87 & $<0.0001$ \\
\hline$x_{1}{ }^{2}$ & 251.93 & 1 & 251.93 & 394.87 & $<0.0001$ \\
\hline$x_{2}^{2}$ & 796.31 & 1 & 796.31 & 1248.10 & $<0.0001$ \\
\hline$x_{3}^{2}$ & 185.65 & 1 & 185.65 & 290.99 & $<0.0001$ \\
\hline Residual & 4.47 & 7 & 0.64 & & \\
\hline Lack of fit & 3.67 & 3 & 1.22 & 6.11 & 0.0565 \\
\hline Pure error & 0.80 & 4 & 0.20 & & \\
\hline $\begin{array}{l}\text { Corrected } \\
\text { total }\end{array}$ & 7621.52 & 16 & & & \\
\hline
\end{tabular}

than 0.0001 showed the terms were highly significant. In contrast, the terms were useless. In this case, $x_{1}, x_{1} x_{2}, x_{1} x_{3}$, were significant model terms and the most significant model term was $x_{2}, x_{3}, x_{2} x_{3}, x_{1}{ }^{2}, x_{2}{ }^{2}, x_{3}{ }^{2}(p<0.0001)$. In general, the value of $R^{2}$ (0.9994) should be higher than 0.80 , which indicated that the model could better explain the 4-NP reduction process. The lack of fit $F$-value of 6.11 was not significant as the $p$-value $(0.0565)$ was $>0.05$. It showed that the model can be successful used to optimize the condition of reduction of 4-NP. Adequate precision measured the ratio between the signal and the noise ${ }^{36}$ and a ratio greater than 4 was desirable. And the ratio of 59.90 indicated that the model can be successfully used to navigate the design space. Table 5 shows the ANOVA data for hydrogel$\mathrm{Ni}$ as catalyst. The model of $F$-value was 16.54 , which implied that the model was significant. The terms of $x_{1}, x_{2}, x_{3}, x_{1} x_{3}, x_{2} x_{3}$, $x_{3}{ }^{2}$ were significant $(p<0.05)$. The model had satisfactory values

Table 5 Analysis of variance (hydrogel-Ni) ${ }^{a}$

\begin{tabular}{llllll}
\hline Source & $\begin{array}{l}\text { Sum of } \\
\text { squares }\end{array}$ & $\begin{array}{l}\text { Degrees of } \\
\text { freedom }\end{array}$ & $\begin{array}{l}\text { Mean } \\
\text { square }\end{array}$ & $F$ value & $\begin{array}{l}p \text {-Value } \\
\text { Prob }>\text { F }\end{array}$ \\
\hline Model & 927.29 & 9 & 103.03 & 16.54 & 0.0006 \\
$x_{1}$ & 47.43 & 1 & 47.43 & 7.61 & 0.0281 \\
$x_{2}$ & 227.88 & 1 & 227.88 & 36.57 & 0.0005 \\
$x_{3}$ & 295.95 & 1 & 295.95 & 47.50 & 0.0002 \\
$x_{1} x_{2}$ & 25.02 & 1 & 25.02 & 4.02 & 0.0851 \\
$x_{1} x_{3}$ & 94 & 1 & 94 & 15.09 & 0.0060 \\
$x_{2} x_{3}$ & 182.44 & 1 & 182.44 & 29.28 & 0.0010 \\
$x_{1}{ }^{2}$ & 2.07 & 1 & 2.07 & 0.33 & 0.5822 \\
$x_{2}{ }^{2}$ & 10.70 & 1 & 10.70 & 1.72 & 0.2315 \\
$x_{3}{ }^{2}$ & 37.73 & 1 & 37.73 & 6.06 & 0.0434 \\
Residual & 43.62 & 7 & 6.23 & & \\
Lack of fit & 24.06 & 3 & 8.02 & 1.64 & 0.3147 \\
Pure error & 19.55 & 4 & 4.89 & & \\
Corrected & 970.91 & 16 & & &
\end{tabular}

total

\footnotetext{
${ }^{a} R$-Squared, 0.9551; adequate precision, 415.52.
} 
of $R^{2}(0.9551)$, could well explain the reduction of 4 -NP and the adequate precision ratio of 415.52 was in the accepted range. What's more, the value of lack of fit was insignificant $(0.3147>0.05)$.

3.3.2 Analysis of the effect of three factors on response. Using BBD design, the interactive effects of every two factors were graphically depicted by $3 \mathrm{D}$ response plots and the optimum values of conditions on reduction of 4-NP were obtained. Fig. 10 and 11 showed three independent response surface plots, which were useful to understand the interaction effects of these factors in the reduction reaction. It was obvious to demonstrate from Fig. 10(a) that when the hydrogel-Cu (B; 0.05-0.15 g) and $\mathrm{NaBH}_{4}$ (C; $0.05-0.15 \mathrm{~g}$ ) increased, the reduction rate of 4-NP increased constantly. The higher reaction rate with increasing amount of $\mathrm{NaBH}_{4}$ could be attributed to the increase in the concentration of hydrogen atoms provided by $\mathrm{NaBH}_{4}$. In addition, hydrogel-Cu promoted the decomposition of $\mathrm{NaBH}_{4}$ and the adsorption of active hydrogen atoms to reduce 4-NP. As shown in Fig. 10(b) and (c), the reduction rate increased slowly when the temperature (A) was in the range from $30{ }^{\circ} \mathrm{C}$ to $48^{\circ} \mathrm{C}$. With the further increasing of the temperature $\left(48-60{ }^{\circ} \mathrm{C}\right)$, the reduction rate went to slightly decrease. The result had verified that the activity of catalyst may be improved at a certain temperature; however, the catalytic performance was affected even deactivated due to high temperature. From the 3D plot (Fig. 11), it was clear that the temperature (A), hydrogel-Ni (B) and $\mathrm{NaBH}_{4}$ (C) had positive effects to the reduction rate of $4-\mathrm{NP}(92.5-96.25 \%, 88-99 \%, 86-98 \%)$. The theoretical description of effects by hydrogel-Ni (B) and $\mathrm{NaBH}_{4}$ (C) were similar to those analyzed in Fig. 10. But the reduction rate increased slightly by $4 \%$ in the range from $30{ }^{\circ} \mathrm{C}$ to $60{ }^{\circ} \mathrm{C}$,

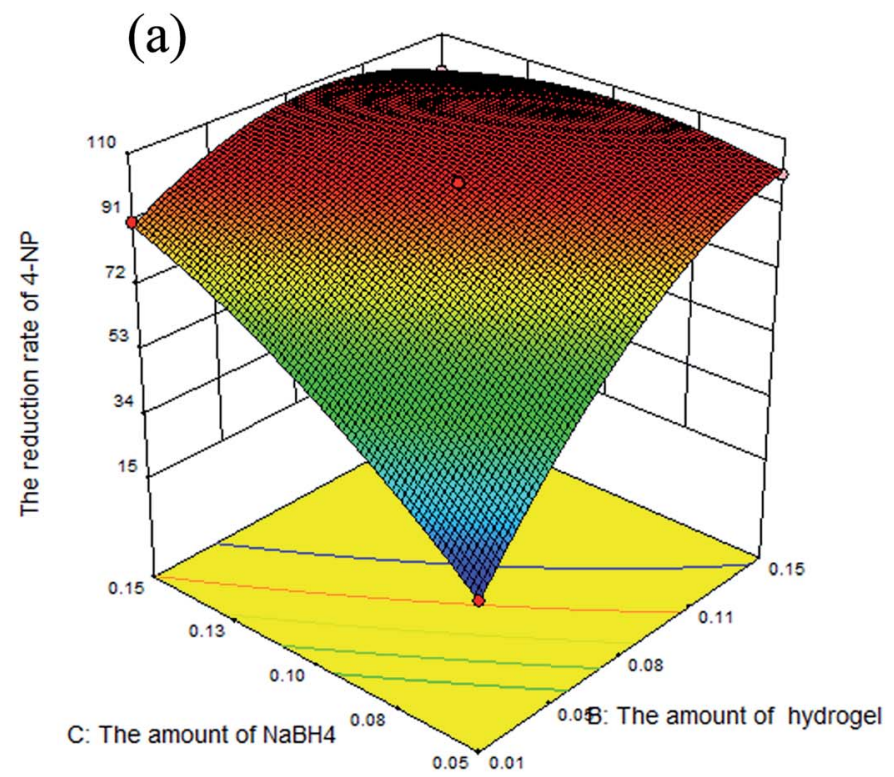

(b)

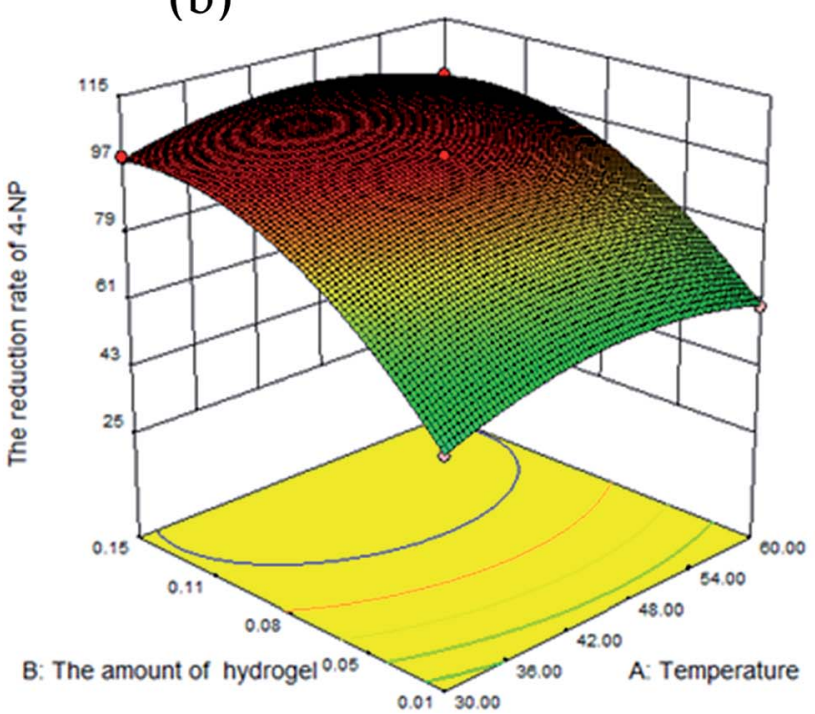

(c)

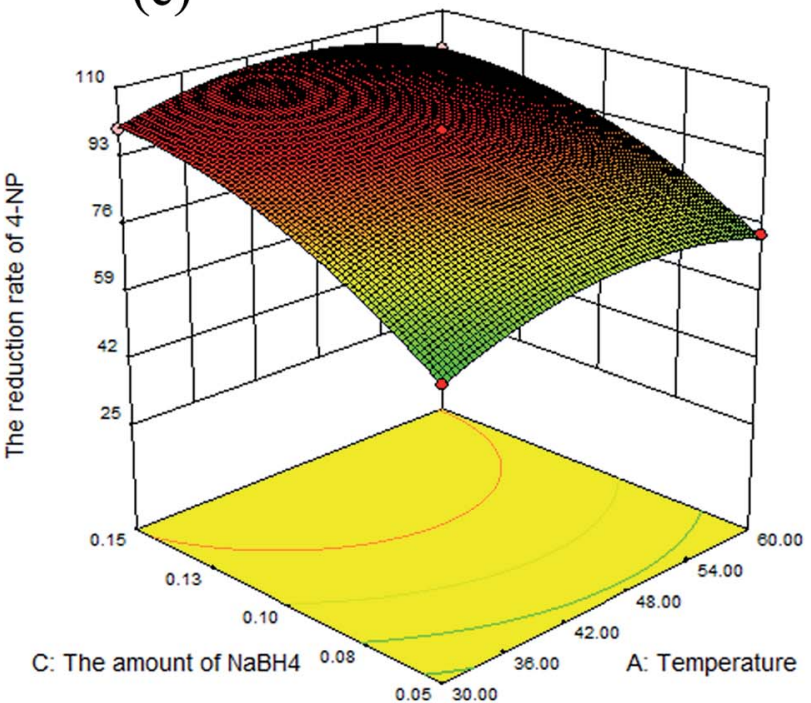

Fig. 103 D response surface graph of the reduction of 4-NP catalyzed by hydrogel-Cu with the interactive effect of variables $\left(x_{1}\right.$ for $A, x_{2}$ for $B, x_{3}$ for C). 


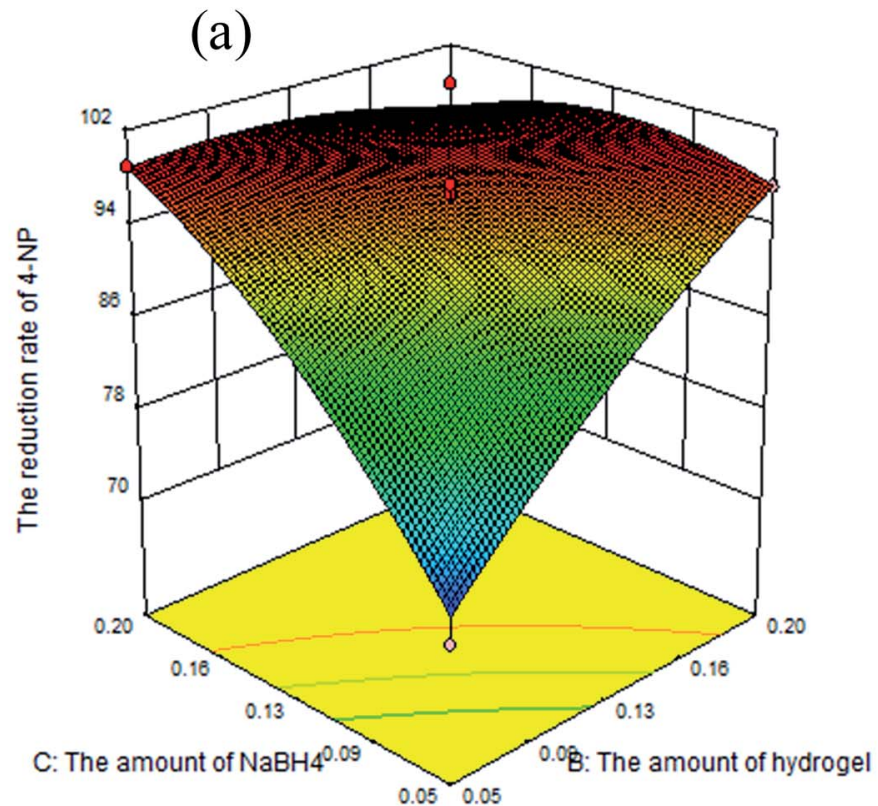

(b)

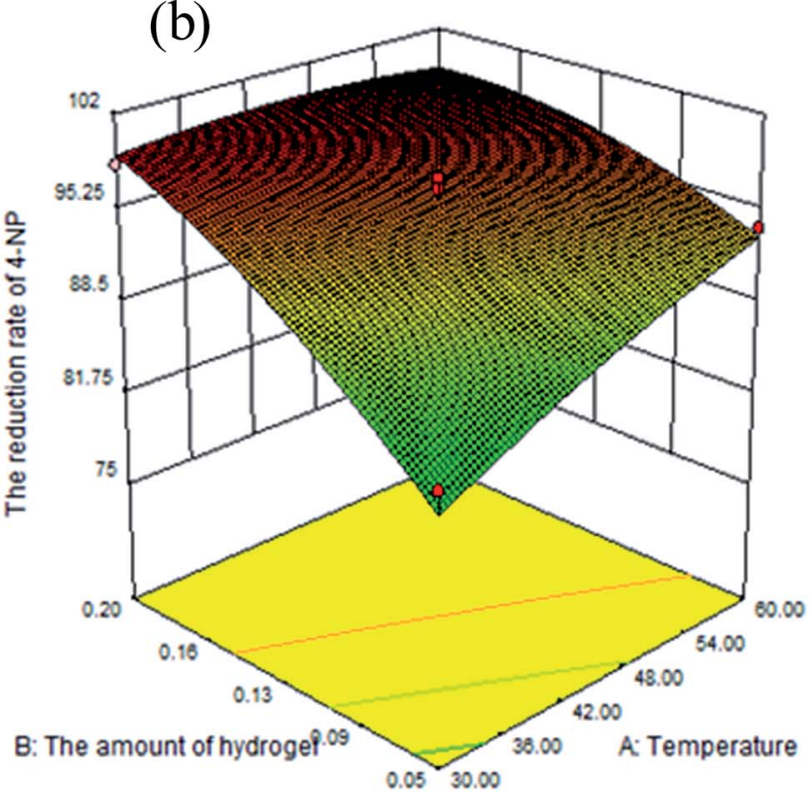

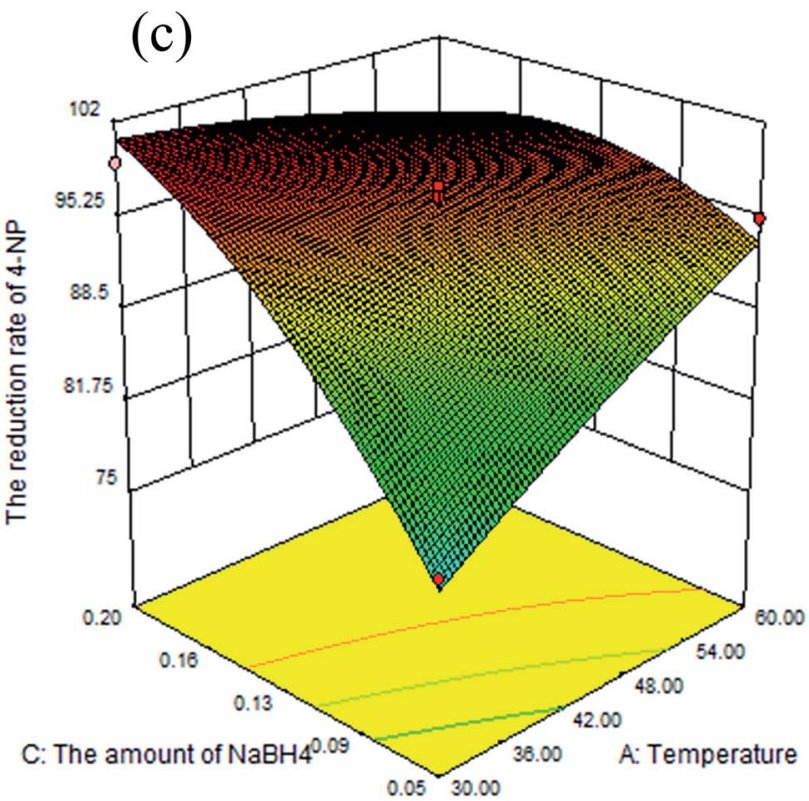

Fig. 11 3D response surface graph of the reduction of 4-NP catalyzed by hydrogel-Ni with the interactive effect of variables $\left(x_{1}\right.$ for $A, x_{2}$ for $B, x_{3}$ for C).

indicating the relative minor impact of temperature on the reaction.

Fig. 10 and 11 depicted approximate spherical response plots; there were local maximum region under the three variables. ${ }^{37}$ So the maximum reduction rate could be obtained. In addition to considering the maximizing result, some other factors were also required, such as economy, feasibility and so on. In virtue of these constraints, the numerical optimization was carried out using BBD including three variables (minimize temperature $\left(x_{1}\right)$, minimize the amount of hydrogel-M $\left(x_{2}\right)$, minimize the amount of $\left.\mathrm{NaBH}_{4}\left(x_{3}\right)\right)$. The optimal conditions were as follows: $0.07 \mathrm{~g}$ hydrogel-Cu with $0.07 \mathrm{~g} \mathrm{NaBH}_{4}$ at
$30{ }^{\circ} \mathrm{C}$ and $0.08 \mathrm{~g}$ hydrogel-Ni with $0.12 \mathrm{~g} \mathrm{NaBH}$ at $30{ }^{\circ} \mathrm{C}$, respectively.

\subsection{Catalytic thermodynamics of the reduction of 4-NP}

The effect of temperature on the reduction of 4-NP to 4-AP with hydrogel-Cu and hydrogel-Ni as catalyst were determined by carrying on the reaction at different temperatures in the range of $30{ }^{\circ} \mathrm{C}$ to $60{ }^{\circ} \mathrm{C}$ and shown in Fig. 12. Using model, the reduction reaction kinetics of 4 -NP can be described as $\ln \left(C / C_{0}\right)=k t$, where $t$ is reaction time, $k$ is pseudo first-order rate constant $\left(\mathrm{min}^{-1}\right)$. $C_{0}\left(\mathrm{mg} \mathrm{L}^{-1}\right)$ and $C\left(\mathrm{mg} \mathrm{L}^{-1}\right)$ are the concentrations of $4-\mathrm{NP}$ at 

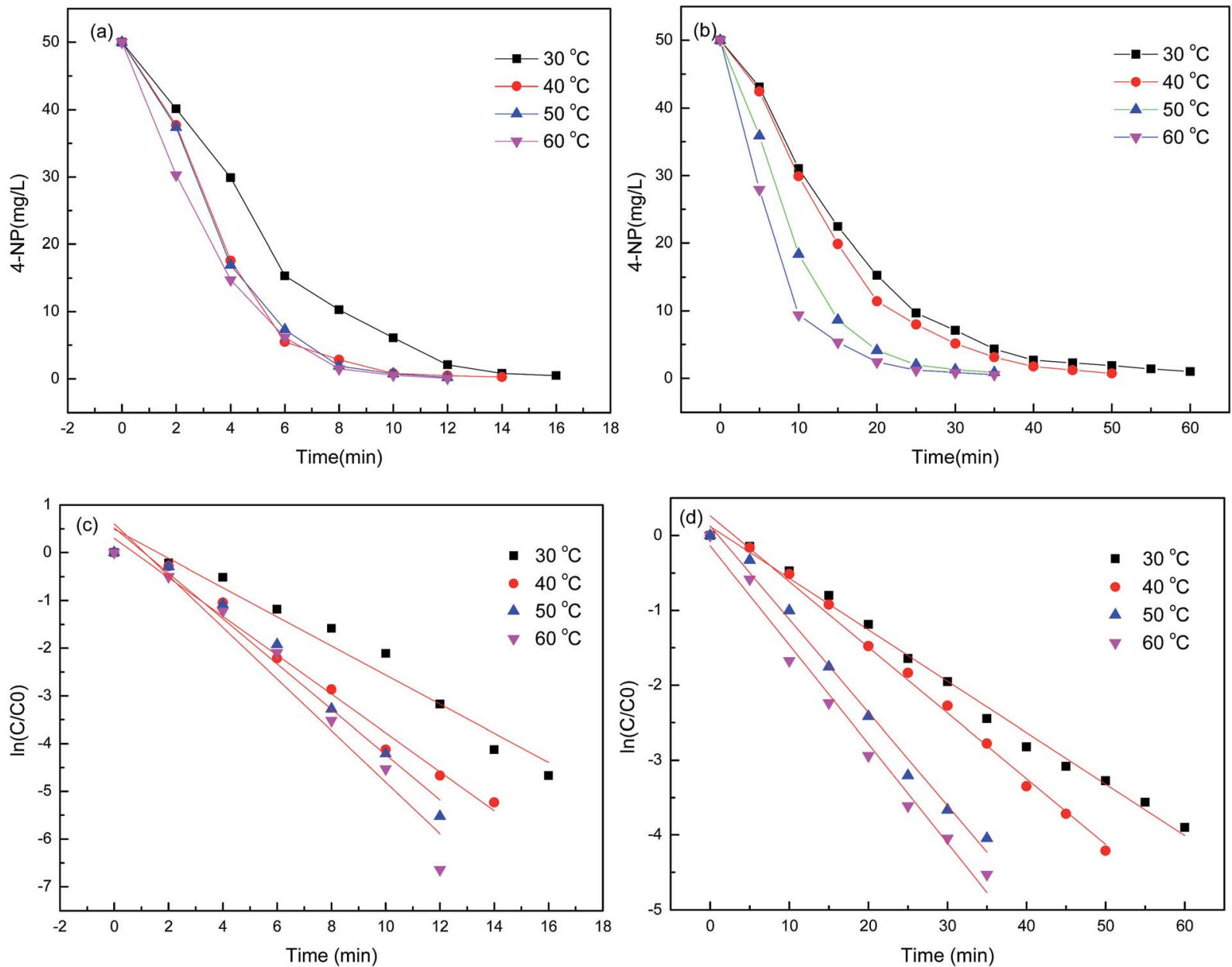

Fig. 12 The changes in the concentration of 4-NP with time in the reduction reaction catalyzed by hydrogel-Cu (a) (c) and hydrogel-Ni (b) (d).

initial and time $t$, respectively. A linear relationship of $\ln \left(C / C_{0}\right)$ $v s$. $t$ corresponding to the reduction catalyzed by hydrogel- $\mathrm{Cu}$ (or Ni) was shown in Fig. 12, respectively, which indicated high correlation with the reduction reaction with all the correlation coefficient above 0.97 . The $k$ for the reduction reaction was calculated from the slope of the straight line and listed in Table 6. It was found that the reduction rate constant increased gradually as the increasing of temperature, indicating the significant influences of temperature on the catalytic reduction for both catalysts. According to the values of $k$ corresponding to different temperatures, the activation parameters of the reduction reactions catalyzed by hydrogel-Cu (Ni) could be obtained by using Arrhenius (eqn (2)) and Eyring equations (eqn (3)).

$$
\begin{gathered}
\ln k=\ln A-\left(\frac{E_{\mathrm{a}}}{R T}\right) \\
\ln \frac{k}{T}=\ln \left(\frac{k_{\mathrm{B}}}{h}\right)+\frac{\Delta S^{\#}}{R}-\frac{\Delta H^{\#}}{R}\left(\frac{1}{T}\right)
\end{gathered}
$$

\begin{tabular}{|c|c|c|c|c|c|c|}
\hline Catalyst & $T\left({ }^{\circ} \mathrm{C}\right)$ & $\begin{array}{l}k \\
\left(\min ^{-1}\right)\end{array}$ & $R^{2}$ & $\begin{array}{l}E_{\mathrm{a}} \\
\left(\mathrm{kJ} \mathrm{mol}^{-1}\right)\end{array}$ & $\begin{array}{l}\Delta H^{\#} \\
\left(\mathrm{~kJ} \mathrm{~mol}^{-1}\right)\end{array}$ & $\begin{array}{l}\Delta S^{\#} \\
\left(\mathrm{~J} \mathrm{~mol}^{-1} \mathrm{~K}^{-1}\right)\end{array}$ \\
\hline \multirow[t]{3}{*}{ Hydrogel-Cu } & 30 & 0.331 & 0.9710 & 17.30 & 14.66 & -205.80 \\
\hline & 50 & 0.527 & 0.9902 & & & \\
\hline & 60 & 0.621 & 0.9618 & & & \\
\hline \multirow[t]{2}{*}{ Hydrogel-Ni } & 30 & 0.069 & 0.9928 & 19.48 & 16.85 & -211.59 \\
\hline & 60 & 0.133 & 0.9851 & & & \\
\hline
\end{tabular}

Table 6 The reduction rate constants of 4-NP at different temperatures and activation parameters catalyzed by hydrogel-Cu and hydrogel-Ni 

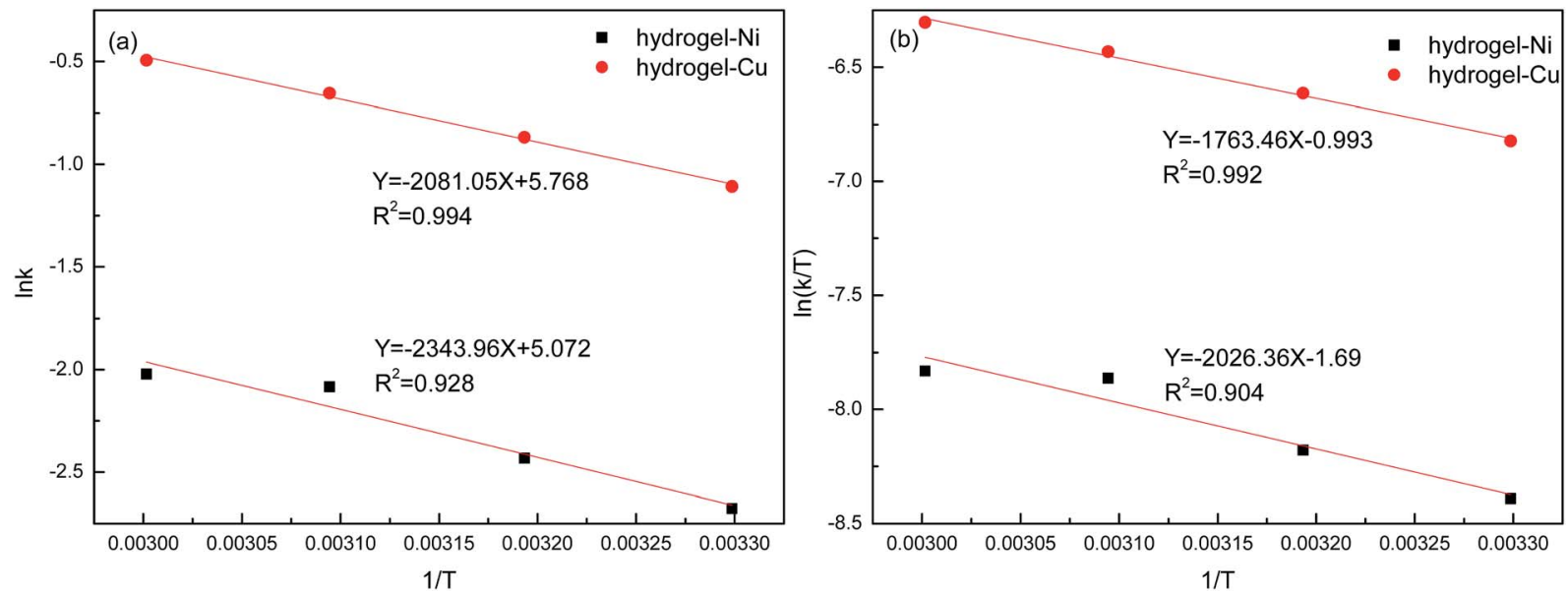

Fig. $13 \ln k$ vs. $1 / T$ (a) and $\ln (k / T)$ vs. 1/T (b) graphs for reduction of 4-NP catalyzed by hydrogel-Cu and hydrogel-Ni.

Table 7 The values of the turnover frequency (TOF) at different temperatures in the reduction reaction catalyzed by hydrogel-Cu and hydrogel-Ni

\begin{tabular}{llll}
\hline Catalyst & $\begin{array}{l}\text { The amount of metal } \\
\text { nanoparticles }(\% \mathrm{~mol})\end{array}$ & $T\left({ }^{\circ} \mathrm{C}\right)$ & $\begin{array}{l}\text { TOF } \\
\left(\mathrm{h}^{-1}\right)\end{array}$ \\
\hline Hydrogel-Cu & 0.2782 & 30 & 3.55 \\
& & 40 & 4.07 \\
& & 50 & 4.76 \\
Hydrogel-Ni & 0.2787 & 60 & 5.72 \\
& & 30 & 0.93 \\
& & 40 & 1.12 \\
& & 50 & 1.61 \\
& & 60 & 1.89
\end{tabular}

where $T$ is the absolute temperature, $R$ is the ideal gas constant $\left(8.314 \mathrm{~J} \mathrm{~K}^{-1} \mathrm{~mol}^{-1}\right), k_{\mathrm{B}}$ is the Boltzmann constant $\left(1.381 \times 10^{-23}\right.$ $\left.\mathrm{J} \mathrm{K}^{-1}\right), h$ is Plank constant $\left(6.626 \times 10^{-34} \mathrm{~J} \mathrm{~s}\right)$, activation energy is $E_{\text {a }}$, activation entropy is $S^{\#}$, activation enthalpy is $H^{\#}$.

And the graphs of $\ln k v s .1 / T$ and $\ln (k / T) v s .1 / T$ were shown in Fig. 13. The activation energy, entropy and activation enthalpy were calculated and summarized in Table 6 . The activation energies were $17.30 \mathrm{~kJ} \mathrm{~mol}^{-1}$ and $19.48 \mathrm{~kJ} \mathrm{~mol}^{-1}$ for hydrogel-Cu and hydrogel-Ni composites as catalyst respectively, and the effect of hydrogel-Cu composites were more effective in the

Table 8 Comparison of catalytic performance of the prepared hydrogel-M ( $\mathrm{M}$ : $\mathrm{Cu}$ or $\mathrm{Ni}$ ) with others in the reported literature

\begin{tabular}{lllll}
\hline $\begin{array}{l}\text { Metal } \\
\text { nanoparticles }\end{array}$ & $\begin{array}{l}\text { Reduction } \\
\text { method }\end{array}$ & $\begin{array}{l}\text { Nitroaromatic } \\
\text { compounds }\end{array}$ & $\begin{array}{l}E_{\mathrm{a}} \\
\left(\mathrm{kJ} \mathrm{mol}^{-1}\right)\end{array}$ & Reference \\
\hline MBS-Cu & $\mathrm{NaBH}_{4}$ & $4-\mathrm{NP}$ & 47.42 & 10 \\
p(SPM)-Cu & $\mathrm{NaBH}_{4}$ & $4-\mathrm{NP}$ & 33.86 & 39 \\
p(AAGA)-Ag & $\mathrm{NaBH}_{4}$ & $4-\mathrm{NP}$ & 33.78 & 1 \\
p(AMPS)-Co & $\mathrm{NaBH}_{4}$ & $4-\mathrm{NP}$ & 27.80 & 14 \\
p(AMPS)-Ni & $\mathrm{NaBH}_{4}$ & $4-\mathrm{NP}$ & 25.70 & 2 \\
p(SPM)-Cu & $\mathrm{NaBH}_{4}$ & $2-\mathrm{NP}$ & 24.96 & 39 \\
WSC-g-PAA/PVA-Ni & $\mathrm{NaBH}_{4}$ & $4-\mathrm{NP}$ & 19.48 & This work \\
WSC-g-PAA/PVA-Cu & $\mathrm{NaBH}_{4}$ & $4-\mathrm{NP}$ & 17.30 & This work
\end{tabular}

reduction reaction. The value of TOF at different temperatures catalyzed by hydrogel-Cu and hydrogel-Ni was determined in Table 7. TOF was defined as the conversion of 4-NP at per surface

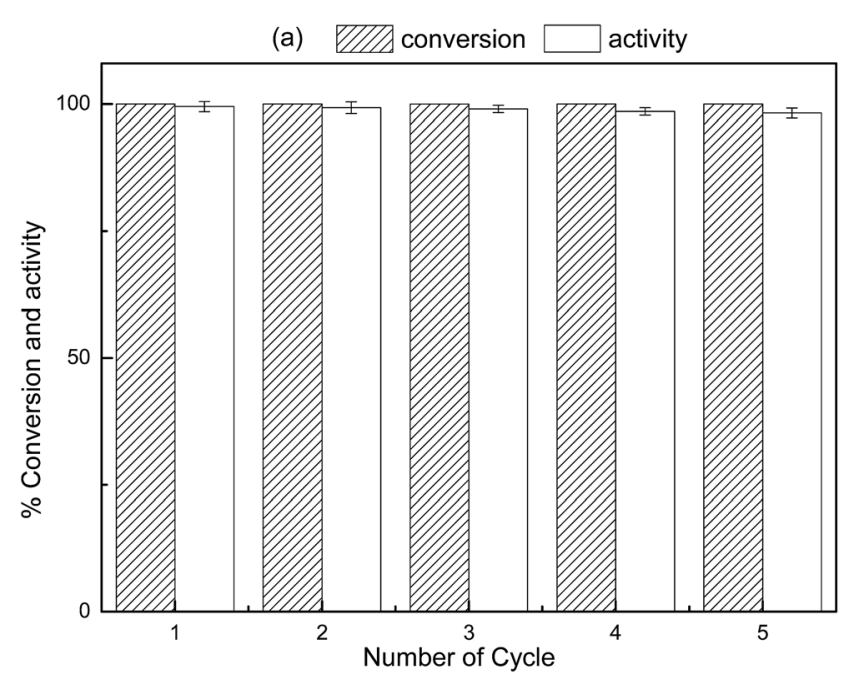

(b)

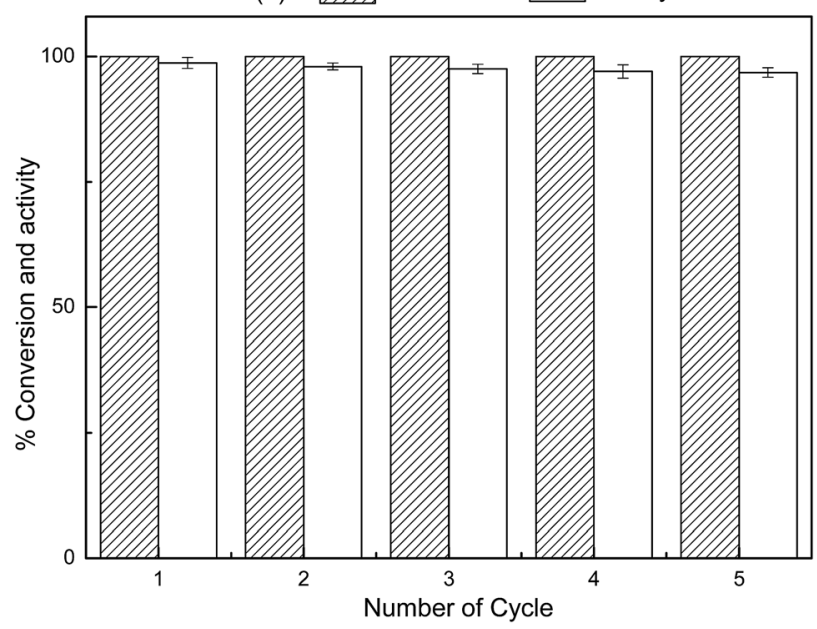

Fig. 14 The change in the conversion and activity of reduction 4-NP for five cycles with hydrogel-Cu (a) and hydrogel-Ni (b) as catalyst. 
metal atom per second. ${ }^{38}$ The value of TOF indicated that the catalytic performance of catalyst increased with the increase of temperature. The result proved that the temperature enhanced the activity of catalyst. Moreover, we have compared the results with others in the literature and the summary of the recent report and our present work in catalytic application, including the kind of metal nanoparticle, reduction method, nitroaromatic compound and the activation energy $\left(E_{\mathrm{a}}\right)$ of hydrogel-Cu/Ni was list in Table 8. It was found that the prepared nanoparticles had a better activity and the activation energy of hydrogel- $\mathrm{Cu} / \mathrm{Ni}$ nanoparticles was lower than that of the recent reports.

\subsection{The reusability and storage capacity of hydrogel-M}

Based on the feasibility of catalyst in practical applications, the reusability and the storage capacity could be determined. To investigate the reusability of hydrogel-M, $0.05 \mathrm{~g}$ WSC-g-PAA/PVA$\mathrm{Cu}$ (or $\mathrm{Ni}$ ) was used in 5 consecutive runs to catalyze the reduction of $200 \mathrm{~mL} 50 \mathrm{mg} \mathrm{L}^{-1}$ aqueous 4-NP solution at $25^{\circ} \mathrm{C}$ in order
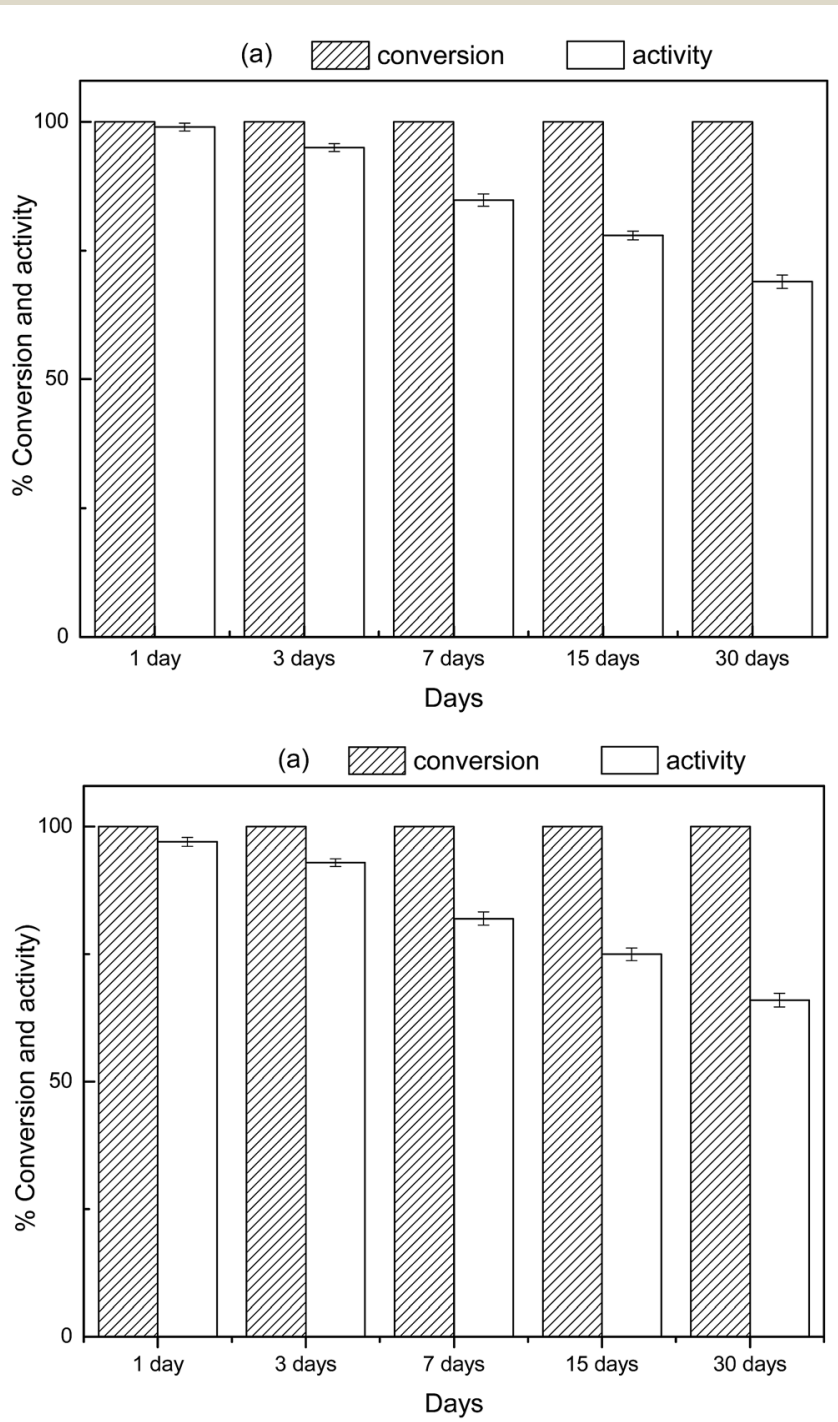

Fig. 15 The effect of storage time on the conversion and activity of hydrogel-Cu (a) and hydrogel-Ni (b). to determine the percent conversion and the activity. Conversion was calculated based on the theoretical value according to 4-NP reduction reaction and activity was estimated by taking the ratios of 4-NP reduction rates for each use to the initial reduction rate. From Fig. 14, it can be seen that $100 \%$ conversion was obtained after each successive use for 4-NP reduction, while the catalytic activity of the hydrogel-M was slowly reduced from $100 \%$ to $98 \%$ for WSC- $g$-PAA/PVA-Cu and $97 \%$ for WSC- $g$-PAA/PVA-Ni at the end of fifth use, respectively. The slight decrease in activity could be due to the accumulation of $\mathrm{NaBO}_{2}$ on the catalyst surface during the $\mathrm{NaBH}_{4}$ hydrolysis. ${ }^{39}$ In addition, the oxidation of the metal nanoparticles by the close proximity of carboxylic acid groups in hydrogel matrices can also lead to the reduction of the catalytic activity of hydrogel-M catalyst. In spite of this, it is worth mentioning that WSC-g-PAA/PVA-Cu (or Ni) still provided better catalytic properties, lower cost and more environmentally friendly compared with conventional hydrogel-M catalyst which posed similar behavior., ${ }^{1,3,39}$

In order to determine the shelf-life of the hydrogel-M, the $\mathrm{Cu}$ or Ni nanoparticles embodied WSC- $g$-PAA/PVA hydrogel were stored in DW with filling nitrogen in closed containers and stored in the dark at $25{ }^{\circ} \mathrm{C}$. The changes in the conversion and activity of WSC-g-PAA/PVA-M in different storage time were tested at the $1 \mathrm{st}, 3 \mathrm{rd}, 7 \mathrm{th}, 15 \mathrm{th}$ and 30 th day and the result was depicted in Fig. 15. After 30 days stored, both WSC-g-PAA/PVA$\mathrm{Cu}$ and WSC- $g$-PAA/PVA-Ni composites can provide 100\% conversion and $70 \%$ activity, which indicated the good storage performance in application. It was attributed to the hydrogel media, which offered a wonderful environment to prevent the aggregation of metal nanoparticles and obstructed the loss of activity compared with bare nanoparticles.

\section{Conclusions}

In this study, $\mathrm{Cu}$ and $\mathrm{Ni}$ nanoparticles in situ preparation inside a semi-IPN WSC-g-PAA/PVA hydrogel were demonstrated and then applied as catalyst system to reduce 4-NP to 4-AP. According to the BBD design, the optimality conditions for the reduction were as follows: $0.07 \mathrm{~g}$ hydrogel-Cu with $0.07 \mathrm{~g} \mathrm{NaBH}_{4}$ at $30{ }^{\circ} \mathrm{C}$ and $0.08 \mathrm{~g}$ hydrogel-Ni with $0.12 \mathrm{~g} \mathrm{NaBH}_{4}$ at $30^{\circ} \mathrm{C}$, respectively. The lower activation energy values confirmed that hydrogel-Cu possessed better catalytic performance than hydrogel-Ni for reduction of 4-NP. The activity slightly changed (about 2-3\%) at the end of the fifth usage and after storage of 30 days, the conversion and activity were almost $100 \%$ and $70 \%$, respectively. These results showed that the WSC- $g$-PAA/PVA-M (Cu or Ni) had great potentials in the future applications.

\section{Acknowledgements}

The authors are grateful for financial support from National Natural Science Foundation of China (21477064 and 21677088), Natural Science Foundation of Shandong Province (ZR2014EEM042), Universities Innovation Projects of Jinan City (20130380) and Young Scholars Program of Shandong University (2015WLJH34). This work was supported by the Taishan Scholar Program (No. ts201511003). 


\section{References}

1 S. Butun and N. Sahiner, Polymer, 2011, 52, 4834-4840.

2 A. Rahman and S. B. Jonnalagadda, Catal. Lett., 2008, 123, 264-268.

3 N. Sahiner, H. Ozay, O. Ozay and N. Aktas, Appl. Catal., A, 2010, 385, 201-207.

4 A. J. Chaudhary and S. M. Grimes, Chemosphere, 2008, 72, 1636-1642.

5 S. Hamidouche, O. Bouras, F. Zermane, B. Cheknane, M. Houari, J. Debord, M. Harel, J.-C. Bollinger and M. Baudu, Chem. Eng. J., 2015, 279, 964-972.

6 G. Busca, S. Berardinelli, C. Resini and L. Arrighi, J. Hazard. Mater., 2008, 160, 265-288.

7 L. Z. Huang, H. C. Hansen and M. J. Bjerrum, J. Hazard. Mater., 2016, 306, 175-183.

8 L. Levin, M. Carabajal, M. Hofrichter and R. Ullrich, Int. Biodeterior. Biodegrad., 2016, 107, 174-179.

9 T.-H. Pham, B.-K. Lee and J. Kim, Process Saf. Environ. Prot., 2016, 104, 314-322.

10 S. Chairam, W. Konkamdee and R. Parakhun, J. Saudi Chem. Soc., 2015, DOI: 10.1016/j.jscs.2015.11.001.

11 R. K. Dhokale, H. M. Yadav, S. N. Achary and S. D. Delekar, Appl. Surf. Sci., 2014, 303, 168-174.

$12 \mathrm{~J}$. Gao, J. $\mathrm{Xu}, \mathrm{S}$. Wen, J. $\mathrm{Hu}$ and H. Liu, Microporous Mesoporous Mater., 2015, 207, 149-155.

13 K. Hareesh, R. P. Joshi, D. V. Sunitha, V. N. Bhoraskar and S. D. Dhole, Appl. Surf. Sci., 2016, 389, 1050-1055.

14 N. Sahiner, H. Ozay, O. Ozay and N. Aktas, Appl. Catal., B, 2010, 101, 137-143.

15 P. Guo, L. Tang, J. Tang, G. Zeng, B. Huang, H. Dong, Y. Zhang, Y. Zhou, Y. Deng, L. Ma and S. Tan, J. Colloid Interface Sci., 2016, 469, 78-85.

16 E. Murugan and R. Rangasamy, J. Polym. Sci., Part A: Polym. Chem., 2010, 48, 2525-2532.

17 N. Sahiner, Prog. Polym. Sci., 2013, 38, 1329-1356.

18 F. Ullah, M. B. Othman, F. Javed, Z. Ahmad and H. Md Akil, Mater. Sci. Eng., C, 2015, 57, 414-433.

19 J. P. de Oliveira, G. Pinheiro Bruni, K. Oliveira Lima, S. Lisie Mello El Halal, G. Silveira da Rosa, A. Renato Guerra Dias and E. da Rosa Zavareze, Food Chem., 2017, 221, 153-160.
20 J. T. Zhang, R. Bhat and K. D. Jandt, Acta Biomater., 2009, 5, 488-497.

21 H. El-Saied, O. A. El-Hady, A. H. Basta, C. Y. El-Dewiny and S. A. Abo-Sedera, J. Saudi Soc. Agric. Sci., 2016, 15, 188-194.

22 J. Liu, Q. Li, Y. Su, Q. Yue and B. Gao, Carbohydr. Polym., 2014, 107, 232-240.

23 A. A. Oun and J. W. Rhim, Carbohydr. Polym., 2016, 150, 187200.

24 J. Zhang, D. Fu, Y. Xu and C. Liu, J. Environ. Sci., 2010, 22, 1281-1289.

25 X. Li, Q. Li, X. Xu, Y. Su, Q. Yue and B. Gao, J. Taiwan Inst. Chem. Eng., 2016, 60, 564-572.

26 Q. Wei, Y. Luo, C. Zhang, L. Fan and Y. Chen, Sens. Actuators, $B, 2008,134,49-56$.

27 F. Fug, C. Nies and W. Possart, Int. J. Adhes. Adhes., 2014, 52, 66-76.

28 Y. Zheng, Y. Liu and A. Wang, Chem. Eng. J., 2011, 171, 12011208.

29 W. U. Yu-Guang, T. H. Zhang, M. X. Xie and G. Zhou, J. Funct. Mater., 2002, 33, 92-96.

30 J. Geng, D. A. Jefferson and B. F. Johnson, Chemistry, 2009, 15, 1134-1143.

31 S. Pourbeyram and S. Mohammadi, J. Non-Cryst. Solids, 2014, 402, 58-63.

32 S. Ghosh, Appl. Catal., A, 2004, 268, 61-66.

33 X.-Q. Wu, X.-W. Wu, Q. Huang, J.-S. Shen and H.-W. Zhang, Appl. Surf. Sci., 2015, 331, 210-218.

34 P. Zhang, Y. Sui, G. Xiao, Y. Wang, C. Wang, B. Liu, G. Zou and B. Zou, J. Mater. Chem. A, 2013, 1, 1632-1638.

35 B. K. Körbahti and M. A. Rauf, Chem. Eng. J., 2008, 136, 2530.

36 A. Özer, G. Gürbüz, A. Çalimli and B. K. Körbahti, Chem. Eng. J., 2009, 146, 377-387.

37 K. Zhong and Q. Wang, Carbohydr. Polym., 2010, 80, 19-25.

38 X. Huang, Y. Li, Y. Li, H. Zhou, X. Duan and Y. Huang, Nano Lett., 2012, 12, 4265-4270.

39 N. Sahiner, A. Kaynak and S. Butun, J. Non-Cryst. Solids, 2012, 358, 758-764. 